OPEN ACCESS

Edited by:

Hao Sun,

University of California, San Diego,

United States

Reviewed by:

James L. Stafford,

University of Alberta, Canada

Maurice Bartlett Hallett,

Cardiff University, United Kingdom

Michael Hickey,

Monash University, Australia

*Correspondence:

Pedro E. Marques

pedro.marques@kuleuven.be

†These authors have contributed equally to this work

Specialty section:

This article was submitted to

Cell Adhesion and Migration,

a section of the journal

Frontiers in Cell and Developmental

Biology

Received: 30 October 2020

Accepted: 15 January 2021

Published: 11 February 2021

Citation:

Vandendriessche S, Cambier $S$ Proost $P$ and Marques PE (2021) Complement Receptors and Their Role in Leukocyte Recruitment and Phagocytosis.

Front. Cell Dev. Biol. 9:624025.

doi: 10.3389/fcell.2021.624025

\section{Complement Receptors and Their Role in Leukocyte Recruitment and Phagocytosis}

\author{
Sofie Vandendriessche ${ }^{\dagger}$, Seppe Cambier ${ }^{\dagger}$, Paul Proost and Pedro E. Marques* \\ Laboratory of Molecular Immunology, Department of Microbiology, Immunology and Transplantation, Rega Institute for \\ Medical Research, Katholieke Universiteit Leuven (KU Leuven), Leuven, Belgium
}

The complement system is deeply embedded in our physiology and immunity. Complement activation generates a multitude of molecules that converge simultaneously on the opsonization of a target for phagocytosis and activation of the immune system via soluble anaphylatoxins. This response is used to control microorganisms and to remove dead cells, but also plays a major role in stimulating the adaptive immune response and the regeneration of injured tissues. Many of these effects inherently depend on complement receptors expressed on leukocytes and parenchymal cells, which, by recognizing complement-derived molecules, promote leukocyte recruitment, phagocytosis of microorganisms and clearance of immune complexes. Here, the plethora of information on the role of complement receptors will be reviewed, including an analysis of how this functionally and structurally diverse group of molecules acts jointly to exert the full extent of complement regulation of homeostasis.

Keywords: complement, complement receptors, leukocyte, inflammation, cell migration, phagocytosis

\section{INTRODUCTION TO THE COMPLEMENT SYSTEM}

\section{Evolution of Complement}

The mammalian complement system comprises more than 50 fluid and membrane-associated proteins that control multiple aspects of physiology and immunity (Hajishengallis et al., 2017). The complement system is classically associated to a rapid response to invading microorganisms, which are either opsonized or directly lysed by the proteolytic cascade of complement proteins, as result of the generation of a lytic membrane attack complex (MAC). Complement is a core component of the immune system and is found (in less complex forms) in invertebrates as ancient as corals, jellyfish and sea anemones (phylum Cnidaria), a suggestion that complement may have originated near the appearance of multicellular organisms (Dishaw et al., 2005; Zhang and Cui, 2014). Complement is also found in invertebrates such as snails and clams (phylum Mollusca), insects and arachnids (phylum Arthropoda) and in the amphioxus (phylum Chordata) (Dodds and Matsushita, 2007; Prado-Alvarez et al., 2009; Sekiguchi and Nonaka, 2015). In vertebrates, complement versions resembling the mammalian system are found in jawed fish, such as zebrafish, in which research on complement function and evolution can be performed (Zhang and Cui, 2014). Although discovered first, the classical pathway (see section The Complement Cascade) is the latest in evolutionary terms, since it is closely associated to the function of IgM and IgG antibodies. Instead, the ancestral complement system likely relied on the combined action of prototypic versions of the complement protein C3, Factor B, and a protease (Nakao and Somamoto, 2016). Interestingly, complement in 
invertebrates and ancestral vertebrates lacks cytolytic activity, which suggests that opsonization was the central role of complement in these animals and that complement-mediated cytolysis appeared later on (Dodds and Matsushita, 2007; Nonaka, 2014).

\section{The Complement Cascade}

The complement system in mammals possesses three main pathways: the classical, the lectin and the alternative pathway (Figure 1) (Densen and Ram, 2015). The classical pathway is initiated by complement protein $\mathrm{Clq}$, which can bind to Fc regions of IgM and IgG immune complexes, but also to a variety of antigens directly through its pattern-recognition capabilities (Kouser et al., 2015). Binding of C1q leads to the activation of the $\mathrm{Clq}$-associated proteases $\mathrm{C} 1 \mathrm{r}$ and $\mathrm{C} 1 \mathrm{~s}$, which will in turn cleave $\mathrm{C} 4$ and $\mathrm{C} 2$ available in the extracellular fluids. Cleavage of $\mathrm{C} 4$ generates $\mathrm{C} 4 \mathrm{~b}$, which binds covalently to molecules in the vicinity of the active $\mathrm{C} 1$ proteases, associating stably to nearby antigens and to the antibodies. The $\mathrm{C} 2$ cleavage fragment $\mathrm{C} 2 \mathrm{a}$ associates with $\mathrm{C} 4 \mathrm{~b}$ to form the $\mathrm{C} 3$ convertase, the central step of complement activation. The C3 convertase will cleave thousands of C3 molecules, present abundantly in the blood, into the highly-reactive $\mathrm{C} 3 \mathrm{~b}$ fragment that associates covalently to neighboring molecules and effectively opsonizes the target (Cooper, 1985). In addition, at this step occurs the release of the other fragment produced during C3 cleavage, the soluble anaphylatoxin $\mathrm{C} 3 \mathrm{a}$, that has pro-inflammatory properties through interaction with its $G$ protein-coupled receptor (GPCR).

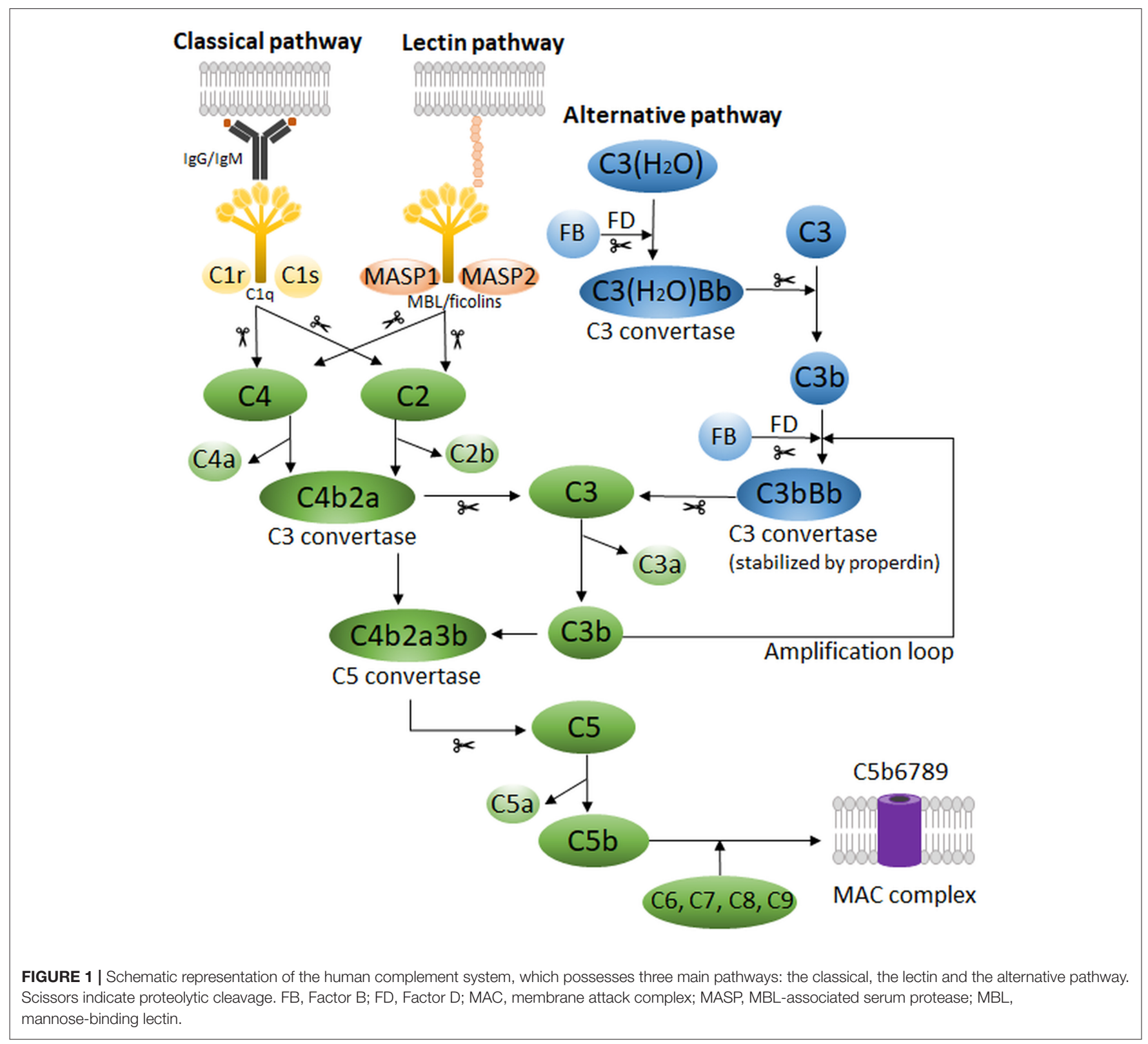


Subsequently, C3b binding to C3 convertases in situ leads to the formation of the $\mathrm{C} 5$ convertases, which are responsible for cleavage of $\mathrm{C} 5$ into $\mathrm{C} 5 \mathrm{~b}$ and $\mathrm{C} 5 \mathrm{a}$. As before, C5b associates to the target, although non-covalently, whereas C5a acts as an anaphylatoxin. The remaining components of the complement cascade; C6, C7, C8, and C9 will associate sequentially to the target-bound $\mathrm{C} 5 \mathrm{~b}$ to form the MAC, which is a pore with cytolytic properties. At its final configuration, the MAC is composed of one copy of C5b, C6, C7, and C8 and up to 18 copies of C9, which constitute the bulk of the MAC pore (Müller-Eberhard, 1986; Merle et al., 2015). The lectin pathway differs from the classical mainly because it is driven by mannose-binding lectin (MBL) and ficolins (Figure 1). Analogously to C1q, they bind to antigens to initiate the complement cascade, but in this case, the antigens are carbohydrates such as mannose, glucose and Nacetyl-glucosamine (Holers, 2014; Merle et al., 2015). Binding of MBL to sugars on microbial membranes leads to activation of MBL-associated serum proteases (MASPs) 1 and 2, which structurally and functionally similar to $\mathrm{C} 1 \mathrm{r}$ and $\mathrm{C} 1 \mathrm{~s}$, will initiate the cleavage of $\mathrm{C} 4$ and $\mathrm{C} 2$ to form the $\mathrm{C} 3$ convertase and unleash the complement cascade.

The complement cascade can also be initiated spontaneously by $\mathrm{C} 3$, the so-called alternative pathway (Figure 1). In the fluid phase, C3 can undergo spontaneous low-rate hydrolysis, or "tickover," to yield $\mathrm{C} 3\left(\mathrm{H}_{2} \mathrm{O}\right)$ (Holers, 2014; Hajishengallis et al., 2017). This form can bind Factor B, which when cleaved by the protease Factor D, produces a fluid-phase C3 convertase $\left[\mathrm{C} 3\left(\mathrm{H}_{2} \mathrm{O}\right) \mathrm{Bb}\right.$. This enzyme produces $\mathrm{C} 3 \mathrm{~b}$ in solution, which may deposit on nearby surfaces and complex with more Factor B, forming the $\mathrm{C} 3$ convertase of the alternative pathway $(\mathrm{C} 3 \mathrm{bBb})$. It is important to mention that this cascade is short-lived and insufficient to promote full complement activation. For that, the alternative pathway requires properdin, a phagocyte-derived protein that stabilizes $\mathrm{C} 3 \mathrm{bBb}$ and allows it to cleave $\mathrm{C} 3$ for long enough to enter the amplification phase of complement activation. Interestingly, the alternative pathway does not require antibodies for initiation, however, the presence of antibodies, polysaccharides, lipopolysaccharides (LPS), gas bubbles, heme, and properdin are all known to facilitate its activation. Moreover, the alternative pathway contributes to the full activation of complement via all pathways (e.g. classical and lectin) by providing an "amplification loop," in which deposited C3b continuously forms new C3 convertases by binding to Factor B. This dramatically increases the cascade activity and is associated to its effects in vivo, including complement-mediated injury (Holers, 2014; Hajishengallis et al., 2017).

\section{Complement Regulation}

Considering the high concentration of complement components in the serum and the ability of the cascade to self-amplify, a number of inhibitory mechanisms and molecules were developed throughout evolution in order to regulate the effects of complement on host cells (Ricklin et al., 2010; Holers, 2014; Densen and Ram, 2015; Merle et al., 2015). The initiation of the cascade is regulated by the $\mathrm{C} 1$ inhibitor (C1-INH/SERPIN 1), which inactivates the $\mathrm{C} 1$ proteases and dissociates them from C1q. Also, C1-INH inhibits several other proteases, including MASPs, thus regulating the lectin pathway. It is worth noting that the C3 convertases are unstable and undergo decay spontaneously, stopping the cascade unless stimuli are present. There are multiple soluble molecules that accelerate the deactivation of convertases, namely: Factor I, a protease that cleaves $\mathrm{C} 3 \mathrm{~b}$ into the enzymatically inactive form iC3b; Factor $\mathrm{H}$, which accelerates the dissociation of $\mathrm{Bb}$ from $\mathrm{C} 3$ convertases and facilitates Factor I cleavage of $\mathrm{C} 3 \mathrm{~b}$; $\mathrm{C} 4$ binding protein (C4BP), which stimulates the dissociation of $\mathrm{C} 2 \mathrm{a}$ from $\mathrm{C} 4 \mathrm{~b}$ (classical C3 convertase) and also acts as co-factor for Factor I-mediated cleavage of $\mathrm{C} 4 \mathrm{~b}$ into $\mathrm{iC} 4 \mathrm{~b}$. Additionally, the soluble proteins clusterin (SP-40) and vitronectin (S protein) bind to nascent C5b-C9 complexes and inhibit MAC assembly. Importantly, the activity of anaphylatoxins $\mathrm{C} 3 \mathrm{a}$ and $\mathrm{C} 5 \mathrm{a}$ is regulated via cleavage by carboxypeptidase- $\mathrm{N}$, a plasma zinc metalloprotease, which cleaves a C-terminal arginine residue that severely reduces the anaphylatoxins' inflammatory effects. There are also a number of membrane-associated complement inhibitors. They serve to restrain the deleterious effects of excessive complement activation, but also offers a means to separate healthy host cells from other complement targets, such as microorganisms, dead cells and crystals, which most often do not express complement inhibitors. These include: Membrane cofactor protein (MCP, $\mathrm{CD} 46$ ), which binds to $\mathrm{C} 3 \mathrm{~b}$ and $\mathrm{C} 4 \mathrm{~b}$ fragments and stimulate Factor I-mediated cleavage; Decay-accelerating factor (DAF, CD55), which dissociates $\mathrm{C} 3$ convertases by binding to $\mathrm{C} 3 \mathrm{~b}$ and C4b; CR1 (CD35), that shares both dissociation and cofactor activities of MCP and DAF; and CD59, which binds C8 and C9 to prevent MAC assembly.

\section{Complement-Associated Diseases and Therapies}

Taking into account its ancient origin and broad reach, it is not surprising that complement regulates central aspects of physiology and immunity. Deficiencies in the complement system predispose individuals to severe recurrent infections and higher incidence of autoimmune disorders as systemic lupus erythematosus (SLE) (Ricklin et al., 2010; Holers, 2014). Conversely, deficiencies in the complement regulatory proteins DAF, MCP, and factor $\mathrm{H}$ lead to paroxysmal nocturnal hemoglobinuria and atypical hemolytic uremic syndrome, conditions in which complement attacks and destroys red blood cells and endothelial cells, respectively. Moreover, complement activation has been implicated in the progression of rheumatoid arthritis and Alzheimer's disease, driven by, respectively, recognition of immune complexes in the joints and amyloid deposits in the brain. Interestingly, it was demonstrated recently that complement gene variants also control the incidence of disorders between males and females (Kamitaki et al., 2020). It was shown that higher levels of C4 and C3 in men are correlated to their higher risk of developing schizophrenia, whereas the lower levels of these proteins in women are correlated to their substantial predisposition to develop SLE. Likewise, a number of treatments targeting complement-mediated diseases have been developed and are currently undergoing clinical trials (Ricklin et al., 2019). Complement inhibitors are being 
evaluated in a variety of kidney diseases (Zipfel et al., 2019), brain injury and neurodegenerative disorders (Brennan et al., 2016), rheumatic diseases (SLE and rheumatoid arthritis) (Trouw et al., 2017), and transplantation (Biglarnia et al., 2018; Thorgersen et al., 2019). Notably, Eculizumab and Ravulizumab (anti-C5 monoclonal antibodies), CCX168 (C5aR receptor antagonist), purified/recombinant C1-INH, and AMY-101 (C3 cleavage inhibitor) have undergone successful phase II/III trials for several diseases. For an extensive review on complement inhibitors in clinical trials see (Mastellos et al., 2019).

Although complement is a self-sustaining cascade with effector functions, the biological effects of complement depend largely on complement receptors. Complement receptors are functionally and structurally diverse, which goes along with their varied roles in leukocyte activation, recruitment, adhesion and phagocytosis. This article aims to review the plethora of information on the role of complement receptors in these functions, with focus on receptor expression, structure and ligand recognition, and connections to effector functions in leukocytes and human disease.

\section{ROLE OF COMPLEMENT RECEPTORS IN LEUKOCYTE RECRUITMENT}

Acute inflammation is a reaction of the host to tissue damage or infection by microorganisms. The inflammatory response is usually beneficial, as it will try to resolve this pathological condition by neutralizing damaging agents so that homeostasis can be restored. Due to recognition of pathogen-associated molecular patterns (PAMPs) or damageassociated molecular patterns (DAMPs), pro-inflammatory chemical mediators will be produced and released by tissueresident cells at the inflammatory site. These mediators including cytokines, chemokines, histamine, prostaglandins and leukotrienes will not only provoke the classical inflammatory symptoms of erythema, heat, pain, and edema but also leukocyte chemotaxis and extravasation into the surrounding inflamed tissue. Once the leukocytes have arrived at the inflammatory site, they can neutralize the inflammatory trigger [by phagocytosis, production of reactive oxygen species (ROS), degranulation, etc.], hence stressing the importance of the leukocyte recruitment process (Medzhitov, 2008). In this section of the review, we will specifically focus on the role of complement receptors in this recruitment process. First, we will focus on the complement anaphylatoxins and their receptors, followed by the role of integrins in leukocyte adhesion and extravasation into the inflamed tissue.

\section{Complement Anaphylatoxins}

Complement fragments $\mathrm{C} 3 \mathrm{a}$ and $\mathrm{C} 5 \mathrm{a}$ are small anaphylatoxins, mediating pro-inflammatory effects by binding to their respective $\mathrm{G}$ protein-coupled complement receptors $\mathrm{C} 3 \mathrm{aR}$ and $\mathrm{C} 5 \mathrm{aR}$. Both human C3a (1-77 amino acids) and C5a (1-74 amino acids) are structurally composed of a core of four $\alpha$-helices stabilized by three disulfide bonds and connected by loop segments (Figure 2) (Huber et al., 1980; Zuiderweg et al., 1989; Zhang et al., 1997). C-terminally in C3a, there is a flexible, cationic, irregular structure (Hugli, 1975; Huber et al., 1980) from which the five final C-terminal amino acids, LGLAR, form the active site of C3a. More specifically, the hydrophobic side chains of leucine-73 and leucine-75 and the guanidinium group of arginine-77 are key in the active site (Caporale et al., 1980). In $\mathrm{C} 5 \mathrm{a}$, the $\alpha$-helical bundle core is connected with a small loop to the five final C-terminal amino acids, that adopt an $\alpha$ helical conformation (Zhang et al., 1997). Interestingly, and in contrast to $\mathrm{C} 3 \mathrm{a}, \mathrm{C} 5 \mathrm{a}$ contains a complex carbohydrate chain N-linked to asparagine-64 (Fernandez and Hugli, 1978). The activity of C3a and C5a is tightly controlled; Carboxypeptidase$\mathrm{N}$ cleaves the carboxy-terminal arginine from both $\mathrm{C} 3 \mathrm{a}$ and $\mathrm{C} 5 \mathrm{a}$ in the bloodstream, reducing their biological activity 10-100 fold [reviewed in (Matthews et al., 2004)]. It is noteworthy that complement fragment $\mathrm{C} 4 \mathrm{a}$ is also considered an anaphylatoxin. Although structurally similar to C3a and C5a (Moon et al., 1981), it lacks an identified complement receptor and its functional capacities are poorly characterized (Barnum, 2015). Recently, it was shown that C4a can act as a ligand for protease-activated receptor (PAR)1 and PAR4, affecting endothelial permeability. However, no role for $\mathrm{C} 4 \mathrm{a}$ in direct leukocyte chemotaxis has been described (Wang et al., 2017).

\section{C3aR}

\section{Receptor characterization}

$\mathrm{C} 3 \mathrm{aR}$ is a cell surface complement receptor part of the GPCR family, first cloned by Ames et al. (1996) and Crass et al. (1996). Its gene $C 3 A R$, only comprising one exon located on chromosome 12p13 (Paral et al., 1998), shares 37\% nucleotide identity throughout the coding regions with $\mathrm{C} 5 \mathrm{aR}$. C3aR is not a classical GPCR as it has an unusually large second extracellular loop ( $\sim 172$ amino acids) between transmembrane domains 4 and 5 (Figure 2) (Ames et al., 1996). Deletion mutagenesis studies showed that multiple aspartate residues in the loop, adjacent to the transmembrane domains, are essential for $\mathrm{C} 3 \mathrm{a}$ binding and the following downstream mobilization of intracellular $\mathrm{Ca}^{2+}$ (Ames et al., 1996; Chao et al., 1999). Indeed, they provide a secondary interaction site through electrostatic interaction with cationic residues in the $\mathrm{C}$-terminal helical region of $\mathrm{C} 3 \mathrm{a}$ (Hugli, 1975; Chao et al., 1999). The primary ligand effector binding site in $\mathrm{C} 3 \mathrm{aR}$, identified to be mainly formed by charged residues in a cluster of transmembrane helices (Sun et al., 1999), is engaged by the active site of C3a being the C-terminal sequence LGLAR (Caporale et al., 1980; Chao et al., 1999). Interestingly, the natural C3a catabolite C3a(desArg) has no binding affinity and cannot activate C3aR (Wilken et al., 1999).

\section{Expression and function in leukocyte recruitment}

The transcript of C3aR is widely expressed in peripheral tissues such as the lung, spleen, ovary, placenta, small intestine, heart, peripheral blood leukocytes and in the central nervous system (Ames et al., 1996). C3aR expression could be identified on neutrophils, basophils, eosinophils, monocytes and mast cells through flow cytometry, northern blotting, calcium release and binding assays (Table 1) (Hartmann et al., 1997; Martin et al., 1997; Zwirner et al., 1999). It was shown however that C3aR 


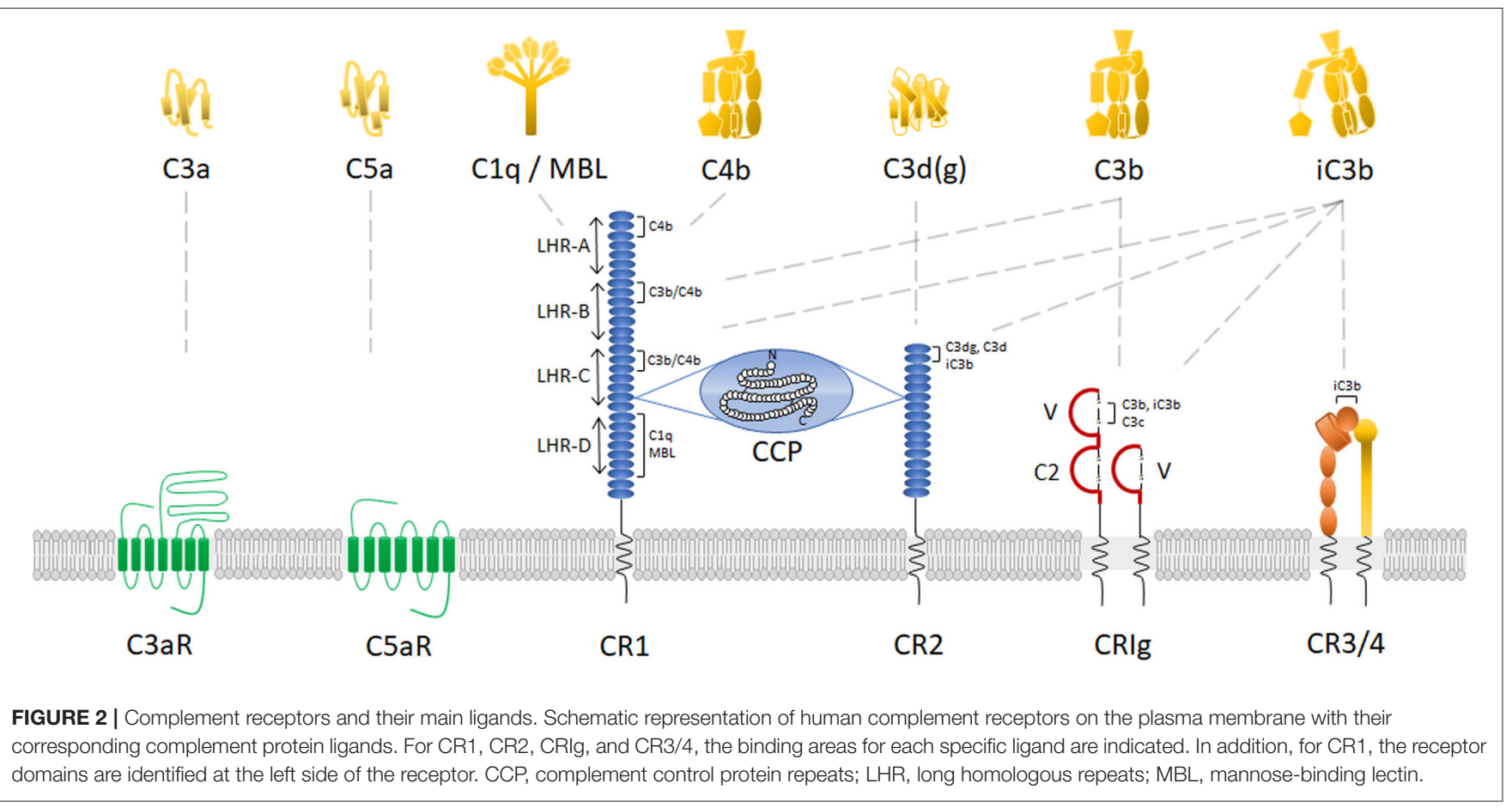

expression on monocytes and neutrophils is about 6 to 20 times lower than C5aR expression, respectively (Zwirner et al., 1999). Receptor expression has not been demonstrated on unchallenged B-lymphocytes and T-lymphocytes (Martin et al., 1997; Zwirner et al., 1999) but expression has been shown on activated Tlymphocytes (Werfel et al., 2000) and on tonsil-derived Blymphocytes (Fischer and Hugli, 1997). Besides leukocytes, expression of $\mathrm{C} 3 \mathrm{aR}$ on bronchial epithelial and smooth muscle cells of the lung has been shown (Drouin et al., 2001). In the central nervous system, C3aR is expressed in astrocytes and microglia during inflammation (Gasque et al., 1998). Moreover, constitutive expression has also been shown on neurons, which suggests a role in physiological conditions (Davoust et al., 1999). In the rat, it was already shown that $\mathrm{C} 3 \mathrm{aR}$ plays a role in the development of the cerebellum (Bénard et al., 2008).

$\mathrm{C} 3 \mathrm{aR}$ activation is associated with $\mathrm{G}$ protein-coupled downstream signaling and an increase in intracellular $\mathrm{Ca}^{2+}$, which is blocked by pertussis toxin (Norgauer et al., 1993; Elsner et al., 1994). Activation of the receptor induces dissociation of the $\mathrm{G} \alpha$ (primarily $\mathrm{G} \alpha_{\mathrm{i}}$ ) subunit and the $\mathrm{G}_{\beta \gamma}$ subunit. $\mathrm{G} \alpha_{\mathrm{i}}$ inhibits adenylyl cyclase, resulting in a reduced intracellular cyclic adenosine monophosphate (cAMP) concentration. $\mathrm{G}_{\beta \gamma}$ activates phospholipase C $\beta$ (PLC $\beta$ ), leading to increased intracellular $\mathrm{Ca}^{2+}$ and protein kinase $\mathrm{C}(\mathrm{PKC})$ activation. In addition, it activates phosphoinositide 3-kinase $\gamma(\mathrm{PI} 3 \mathrm{~K} \gamma)$ resulting in activation of extracellular signal-regulated kinases (ERKs) and phosphokinase B (Akt) (Futosi et al., 2013). This signaling cascade, has been shown to induce chemotaxis of mast cells (Hartmann et al., 1997) and eosinophils (Daffern et al., 1995). Induction of macrophage chemotaxis by C3a was first shown in the mouse macrophage cell line J774 (Zwirner et al., 1998). Activation of C3aR does not induce direct neutrophil chemotaxis (Fernandez et al., 1978; Elsner et al., 1994; Daffern et al., 1995). However, C3a was able to induce ROS production in neutrophils (Elsner et al., 1994) and C3aR activation also induced formation of neutrophil extracellular traps (NETosis), leading to hypercoagulation and tumor-promoting effects in vivo (Guglietta et al., 2016). Wu et al. reported a role for $\mathrm{C} 3 \mathrm{aR}$ as inhibitor of neutrophil mobilization and protection from intestinal ischemia-reperfusion injury. Indeed, $\mathrm{C}_{3} \mathrm{aR}^{-/-}$mice had an augmented number of tissueinfiltrating and circulating neutrophils, which were associated to worsening of intestinal damage, whereas stimulation of $\mathrm{C} 3 \mathrm{aR}$ in WT mice reduced neutrophil mobilization and consequent intestinal injury (Wu et al., 2013). An interesting study showed a role for $\mathrm{C} 3 \mathrm{a}$ in the retention of hematopoietic stem cells in the bone marrow. C3a-C3aR interaction can counteract mobilization of hematopoietic stem cells by increasing their response to stromal-derived factor 1 (SDF-1/CXCL12), of which the expression decreases in the bone marrow during mobilization (Reca et al., 2003; Ratajczak et al., 2004). In the central nervous system, it was shown using $\mathrm{C} 3^{-/-}$and $\mathrm{C} 3 \mathrm{aR}^{-/-}$mice that $\mathrm{C} 3 \mathrm{a}$ plays a role in cerebral endothelial activation (by upregulation of adhesion molecules) and leukocyte recruitment to the LPSinflamed brain (Wu et al., 2016). Also, a specific link between $\mathrm{C} 3 \mathrm{a}$ and depression was found. In mice, it was shown that C3a induces monocyte infiltration into the prefrontal cortex after exposure to chronic stress, which is specifically associated with depressive-like behavior (Crider et al., 2018). Interestingly, $\mathrm{C} 3 \mathrm{a}-\mathrm{C} 3 \mathrm{aR}$ interaction promotes monocyte recruitment into inflamed skeletal muscle. There, it plays an essential role during regeneration of skeletal muscle, as this regeneration can be impaired by $\mathrm{C} 3 \mathrm{a}$ inactivation or $\mathrm{C} 3 \mathrm{aR}$ deletion (Zhang et al., 
TABLE 1 | Expression, function and main ligands of complement receptors.

\begin{tabular}{|c|c|c|c|c|}
\hline Receptor & Alternative name & Main ligands & $\begin{array}{l}\text { Main leukocyte } \\
\text { expression }\end{array}$ & Main functions \\
\hline $\mathrm{C} 3 \mathrm{aR}$ & / & Сза & $\begin{array}{l}\text { Neutrophils } \\
\text { Basophils } \\
\text { Eosinophils } \\
\text { Monocytes } \\
\text { Mast cells } \\
\text { Activated } \\
\text { T-lymphocytes } \\
\text { Tonsil-derived B- } \\
\text { lymphocytes }\end{array}$ & $\begin{array}{l}\text { Chemotaxis of mast cells, eosinophils and } \\
\text { monocytes/macrophages (Daffern et al., 1995; Hartmann } \\
\text { et al., 1997; Zwirner et al., 1998) } \\
\text { Induction of ROS production in neutrophils (Elsner et al., } \\
\text { 1994) } \\
\text { No (or inhibition of) chemotaxis of neutrophils (Daffern et al., } \\
\text { 1995; Wu et al., 2013) } \\
\text { Retention of hematopoietic stem cells in the bone marrow } \\
\text { (Reca et al., 2003; Ratajczak et al., 2004) } \\
\text { Leukocyte recruitment to the brain (Wu et al., 2016; Crider } \\
\text { et al., 2018) } \\
\text { Regeneration of skeletal muscle and hepatic tissue (Strey } \\
\text { et al., 2003; Markiewski et al., 2004; Zhang et al., 2017) }\end{array}$ \\
\hline C5L2 & C5aR2 & C5a & $\begin{array}{l}\text { Immature dendritic } \\
\text { cells } \\
\text { Granulocytes (Myeloid } \\
\text { immune cells) } \\
\text { T cell subsets }\end{array}$ & $\begin{array}{l}\text { Immune suppressing and immune activating functions due to } \\
\text { regulation of C5aR activation and signaling (Li et al., 2019) }\end{array}$ \\
\hline CR1 & $\begin{array}{l}\text { CD35 } \\
\text { C3b/C4b receptor }\end{array}$ & $\begin{array}{l}\text { C1q } \\
\text { C3b } \\
\text { C4b } \\
\text { iC3b } \\
\text { MBL }\end{array}$ & $\begin{array}{l}\text { Erythrocytes } \\
\text { Monocytes/macrophages } \\
\text { Granulocytes } \\
\text { B-lymphocytes } \\
\text { CD4+ T-lymphocytes } \\
\text { FDCs } \\
\text { Glomerular podocytes }\end{array}$ & $\begin{array}{l}\text { Immune regulatory role (lida and Nussenzweig, 1981; Masaki } \\
\text { et al., 1992) } \\
\text { Immune-complex clearance (Cornacoff et al., 1983) } \\
\text { Phagocytosis (Fällman et al., 1993) }\end{array}$ \\
\hline CR2 & CD21 & $\begin{array}{l}\text { iC3b } \\
\text { C3dg } \\
\text { C3d } \\
\text { gp350/220 (EBV) } \\
\text { CD23 } \\
\text { Interferon-alpha }\end{array}$ & $\begin{array}{l}\text { B-lymphocytes } \\
\text { FDCs } \\
\text { T-lymphocytes } \\
\text { Epithelial cells }\end{array}$ & $\begin{array}{l}\text { Lowering B-lymphocyte activation threshold (Carter and } \\
\text { Fearon, 1992) } \\
\text { Retention of C3-opsonized antigens (Reynes et al., 1985) } \\
\text { Promotion of B-lymphocyte class switching and IgE } \\
\text { production (Aubry et al., 1992) } \\
\text { EBV cell entry (Tanner et al., 1987) }\end{array}$ \\
\hline CR3 & $\begin{array}{l}\text { Mac-1 } \\
\text { CD11b/CD18 } \\
\text { Integrin } \alpha_{M} \beta_{2}\end{array}$ & $\begin{array}{l}\text { ICAM-1 } \\
\text { ICAM-2 } \\
\text { Fibrinogen } \\
\text { iC3b } \\
\text { Collagen } \\
\text { Factor X } \\
\text { NIF }\end{array}$ & $\begin{array}{l}\text { Neutrophils } \\
\text { Monocytes/macrophages } \\
\text { Dendritic cells } \\
\text { NK cells } \\
\text { Activated lymphocytes }\end{array}$ & $\begin{array}{l}\text { Leukocyte extravasation (Dustin and Springer, 1988; } \\
\text { Meerschaert and Furie, 1995; Ding et al., 1999; Phillipson } \\
\text { et al., 2006) } \\
\text { Phagocytosis (Beller et al., 1982) }\end{array}$ \\
\hline CR4 & $\begin{array}{l}\text { p150,95 } \\
\text { CD11c/CD18 } \\
\text { Integrin } \alpha_{\times} \beta_{2}\end{array}$ & $\begin{array}{l}\text { ICAM-1 } \\
\text { ICAM-2 } \\
\text { Fibrinogen } \\
\text { iC3b } \\
\text { Collagen } \\
\text { Factor X } \\
\text { NIF }\end{array}$ & $\begin{array}{l}\text { Neutrophils } \\
\text { Monocytes/macrophages } \\
\text { Dendritic cells } \\
\text { NK cells } \\
\text { Activated lymphocytes }\end{array}$ & $\begin{array}{l}\text { Adhesion to fibrinogen (Sándor et al., 2016) } \\
\text { Phagocytosis (Keizer et al., 1987) }\end{array}$ \\
\hline
\end{tabular}

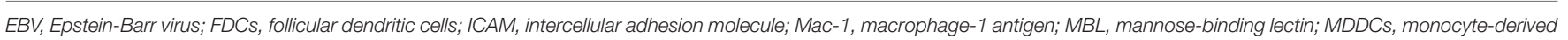
dendritic cells; NIF, neutrophil inhibitory factor; NK, natural killer; ROS, reactive oxygen species; VSIG4, V-set and Ig domain 4. 
2017). C3a is also involved in the regeneration of hepatic tissue after injury. After partial hepatectomy in $\mathrm{C} 3^{-/-}$mice, normal liver regeneration was impaired, which was associated with clinical deterioration and higher mortality compared to WT mice (Strey et al., 2003). Moreover, liver regeneration was impaired after a toxic challenge in $\mathrm{C}^{-/-}$mice. This could however be reversed by administration of $\mathrm{C} 3 \mathrm{a}$ and activation of $\mathrm{C} 3 \mathrm{aR}$ (Markiewski et al., 2004).

\section{C5aR}

\section{Receptor characterization}

C5aR (C5aR1 or CD88) is a cell surface GPCR first discovered in 1991 (Figure 2) (Gerard and Gerard, 1991). The gene C5AR1 comprises two exons and is located on chromosome 19, band position q13.3 (Gerard et al., 1993). C5aR is bound by its ligand complement fragment $\mathrm{C} 5 \mathrm{a}$ according to a two-site binding model (Siciliano et al., 1994). The extracellular N-terminal portion of C5aR [with required aspartic acids (DeMartino et al., 1994) and sulfations of N-terminal tyrosines (Farzan et al., 2001)] is essential in the formation of the docking site for the core of C5a via electrostatic interactions (Mery and Boulay, 1994; Siciliano et al., 1994). Interaction of C5a with the N-terminal part of the receptor is required for high affinity binding and full activation of the receptor (DeMartino et al., 1994). However, just as in the $\mathrm{C} 3 \mathrm{a}-\mathrm{C} 3 \mathrm{aR}$ interaction, the primary ligand binding site is located between the transmembrane helices at the base of the C5aR extracellular loops. This binding site interacts with the Cterminal part of C5a (Siciliano et al., 1994). In line with this, C-terminal peptide fragments of $\mathrm{C} 5 \mathrm{a}$ are sufficient to activate $\mathrm{C} 5 \mathrm{aR}$, even if the receptor is $\mathrm{N}$-terminally truncated. It is believed that the interaction between $\mathrm{C} 5 \mathrm{a}$ and the $\mathrm{N}$-terminal part of $\mathrm{C} 5 \mathrm{aR}$ is essential to induce a conformational change in C5a, which allows its C-terminal part to interact with and to activate the receptor (DeMartino et al., 1994). Interestingly, the highest residue homology with $\mathrm{C} 3 \mathrm{aR}$ is found in the transmembrane domains and in the second intracellular loop (Ames et al., 1996). Later on, it was shown via receptor mutagenesis that arginine206 located in the 5th transmembrane helix of C5aR is essential for high-affinity binding to C5a (Raffetseder et al., 1996).

\section{Expression and function in leukocyte recruitment}

The C5aR transcript is co-expressed with C3aR in several peripheral tissues such as the lung, spleen, placenta and the central nervous system. C5aR is expressed to a higher extent than $\mathrm{C} 3 \mathrm{aR}$ in peripheral blood leukocytes and the heart (Table 1) (Ames et al., 1996). More specifically, its expression was described on human polymorphonuclear leukocytes in Chenoweth and Hugli (1978) and on murine macrophages in Chenoweth et al. (1982). Nevertheless, induction of directed chemotaxis of polymorphonuclear leukocytes by C5a had already been shown in vitro and in simulated in vivo conditions before the receptor was known (Shin et al., 1968; Fernandez et al., 1978). Later on, with the use of polyclonal antibodies directed against the extracellular N-terminal part of C5aR, inhibition of C5a-mediated neutrophil chemotaxis and -degranulation, and inhibition of cytokine production by monocytes was demonstrated (Morgan et al., 1993). Furthermore, C5a can induce production of ROS in granulocytes, which resulted in endothelial cell cytotoxicity in vitro (Sacks et al., 1978). Moreover, C5a-C5aR interaction plays a specific role in neutrophil and monocyte migration to the synovium of rheumatoid and psoriatic arthritis patients (Hornum et al., 2017). In a mouse model of autoantibody-induced inflammatory arthritis, activation of $\mathrm{C} 5 \mathrm{aR}$ on neutrophils in the joint vasculature perpetuates their own recruitment. Indeed, C5a production due to complement opsonization on immune complexes in the joints, results in release of the chemotactic lipid leukotriene B4 (LTB4) from arrested neutrophils which promote further neutrophil migration to the interstitium (Sadik et al., 2018). Functional expression of $\mathrm{C} 5 \mathrm{aR}$ has also been shown on dendritic cells (Sozzani et al., 1995) and skin mast cells. Expression of C5aR was specifically associated with histamine release after C5a stimulation (Johnson et al., 1975; Füreder et al., 1995). Conversely, expression of C5aR on human T-lymphocytes was relatively low, but T-lymphocytes are responsive to a C5a gradient when receptor expression is increased by phytohemagglutinin stimulation (Nataf et al., 1999). Ottonello et al. also showed low expression of C5aR on naive and memory B-lymphocytes, which was sufficient to promote a response to recombinant $\mathrm{C} 5 \mathrm{a}$ in vitro (Ottonello et al., 1999). However, on murine (un)stimulated T- or B-lymphocytes no expression of C5aR was observed, in contrast to granulocytes and macrophages (Soruri et al., 2003).

Besides leukocytes, C5aR is expressed in several cell types of the lung (lung vascular smooth muscle, endothelium, bronchial and alveolar epithelium) and in liver parenchymal cells (Haviland et al., 1995; Drouin et al., 2001). Together with C3a, C5a-C5aR interaction is required in liver regeneration. Indeed, $\mathrm{C} 5^{-/-}$mice display abnormal liver regeneration after partial hepatectomy or toxic injury (Mastellos et al., 2001; Strey et al., 2003). Moreover, mice deficient in both C3 and C5 have an even more severe defect in regeneration, which can be partially reversed by reconstitution with $\mathrm{C} 3 \mathrm{a}$ or $\mathrm{C} 5 \mathrm{a}$. Administration of both anaphylatoxins together led to a better recovery, suggesting that C3a and C5a act cooperatively in the early priming stages of hepatocyte regeneration. Furthermore, in a rat model of partial hepatectomy, C5aR was upregulated on hepatocytes promoting their regrowth after injury (Daveau et al., 2004). Blockade of $\mathrm{C} 5 \mathrm{aR}$ reduces the intrahepatic release of interleukin-6 (IL-6) and tumor necrosis factor alpha (TNF- $\alpha$ ). However, in contrast to their inflammatory roles in most tissues, these cytokines are essential for hepatocytes to reenter the cell cycle and initiate liver regeneration via activation of the transcription factors nuclear factor kappa-light-chain-enhancer of activated B cells $(\mathrm{NF}-\kappa \mathrm{B})$ and signal transducer and activator of transcription 3 (STAT-3) (Strey et al., 2003). Interestingly, the site-targeted murine complement inhibitor CR2-CD59 (which specifically inhibits the assembly of the MAC) is able to promote hepatocyte proliferation, and so, liver regeneration after hepatectomy. CR2CD59 can increase the intrahepatic IL-6 and TNF- $\alpha$ levels, resulting in STAT-3 and Akt activation required for liver regeneration (Marshall et al., 2014). 


\section{C5L2}

Human C5a receptor-like 2 (C5L2 or C5aR2) is a seventransmembrane spanning receptor related to the $\mathrm{C} 5 \mathrm{a}$ and $\mathrm{C} 3 \mathrm{a}$ receptor, first discovered in 2000 in immature dendritic cells and granulocytes (Ohno et al., 2000). Expression was also described in the bone marrow, spleen, lung, in most myeloid immune cells and $\mathrm{T}$ cell subsets, and it is present both intracellularly and on the cell surface (Li et al., 2019). C5L2 is able to bind $\mathrm{C} 5 \mathrm{a}$ and hence functions as a second $\mathrm{C} 5 \mathrm{a}$ receptor (Okinaga et al., 2003). However, it lacks the ability to induce downstream signaling due to an amino acid $(\mathrm{R} \rightarrow \mathrm{L})$ replacement in the DRY motif. This highly conserved motif, located at the end of the third transmembrane segment, is necessary for GPCR interaction with $\mathrm{G}$ proteins. As a consequence, C5L2 is unable to induce downstream signaling and calcium increase, and it may function as a decoy receptor (Okinaga et al., 2003). Several studies however reported C5L2 as an important regulator of C5aR activation and downstream signaling. Bamberg et al. indicated that C5L2 might function as a negative modulator of ERK1/2 signal transduction through modulation of $\beta$-arrestin after $\mathrm{C} 5 \mathrm{aR}$ activation by $\mathrm{C} 5 \mathrm{a}$. Inhibition of $\mathrm{C} 5 \mathrm{~L} 2$ resulted in increased C5a-mediated chemotaxis, but no alterations in C5a-induced $\mathrm{Ca}^{2+}$-responses (Bamberg et al., 2010). It was also shown that C5L2 can physically interact with C5aR, forming heterodimers (Croker et al., 2013). Thus, C5a stimulation may trigger C5aRC5L2 heterodimerization and $\beta$-arrestin recruitment, facilitating C5aR internalization and downregulating C5aR-mediated ERK signaling (Croker et al., 2014; Li et al., 2019). In contrast, it has been shown that C5L2 also exerts stimulatory functions: On the endothelium, it promotes $\mathrm{C} 5 \mathrm{a}$ translocation into the blood vessel lumen, mediating neutrophil arrest through $\mathrm{C} 5 \mathrm{aR}$ activation in a murine arthritis model (Miyabe et al., 2019). More elaborated information about the current knowledge of this controversial receptor and its role in pathophysiology was recently reviewed by Li et al. (2019).

\section{$\beta_{2}$-Integrin Family Complement Receptors CR3 and CR4 \\ Receptor Characterization}

In contrast to the chemotactic receptors $\mathrm{C} 3 \mathrm{aR}$ and $\mathrm{C} 5 \mathrm{aR}$, $\beta 2$-integrins are heterodimeric cell surface adhesion receptors that play a crucial role in cell adhesion, migration and communication. They are involved in cell-cell and cellextracellular matrix interactions and have the unique capacity to mediate bidirectional transmission of mechanical and biochemical signals across the membrane. Structurally, integrins are characterized by a non-covalent association of two type I membrane glycoproteins, the $\alpha$ and $\beta$ subunit, consisting of a small cytoplasmic tail ( $<75$ amino acids, except for the $\beta 4$ subunit), a transmembrane region and a large extracellular domain containing ligand-binding sites $(>100 \mathrm{kDa}$ for $\alpha$ subunits and $>75 \mathrm{kDa}$ for $\beta$ subunits) (Hynes, 1992). The subunits form together an extracellular domain composed of a N-terminal globular ligand-binding head and a C-terminal tailpiece, formed by two long "legs" or "stalks", connecting with the transmembrane and short cytoplasmic domains of each subunit (Nermut et al., 1988) (Figure 2). The N-terminal region of the $\alpha$-domain contains seven segments of about 60 amino acids, which fold into a seven-bladed $\beta$-propeller domain that forms the globular head region of the receptor. About half of the integrins, more specifically the leukocyte $\beta_{2}$-integrins and the integrin collagen receptors, have an approximately 200 amino acid insertion in between the second and third beta sheet that is known as the inserted (I) domain. This domain contains a metal ion-dependent adhesion site (MIDAS) for binding of divalent cations required for ligand binding (Diamond et al., 1993; Michishita et al., 1993; Lee et al., 1995; Tuckwell et al., 1995). The leukocyte $\beta_{2}$-integrin family includes four members that share a common $\beta_{2}$-subunit (CD18) linked to one of four $\alpha$-chains: $\alpha \mathrm{L} \beta_{2}$-integrin [also referred to as lymphocyte functionassociated antigen 1 (LFA-1) or CD11a/CD18], $\alpha \mathrm{M} \beta_{2}$-integrin [macrophage-1 antigen (Mac-1), CR3 or CD11b/CD18], $\alpha \mathrm{X} \beta_{2^{-}}$ integrin [p150,95; CR4 or CD11c/CD18] and $\alpha \mathrm{D} \beta_{2}$-integrin [CD11d/CD18] (Springer et al., 1979; Kürzinger et al., 1981; Sanchez-Madrid et al., 1983; Van der Vieren et al., 1995). Within the $\beta 2$-integrin family, there are two complement receptors: CR3 and CR4 (Table 1).

\section{Expression and Function in Leukocyte Recruitment}

Leukocyte recruitment to tissues is an essential step in the inflammatory response that requires the binding and extravasation of leukocytes in the vasculature. In the muscle and intestines, it starts with rolling of the leukocyte over the activated endothelium, followed by leukocyte activation and firm adhesion, diapedesis through the endothelial layer and further migration into the tissue matrix (Figure 3) (Muller, 2013). Integrins play a crucial role in this complex and tightly controlled process. In steady state, passively moving blood leukocytes express bent, non-activated "resting" integrins. In this conformation, the ligand-binding head domain of the integrin is folded over the tailpiece, moving the ligand binding site close to the C-terminal, membrane-proximal end of the tailpiece ("legs" of the integrin). This is an unfavorable orientation for ligand binding and consequently bent integrins have only low affinity for their endothelial ligands, including the immunoglobulin superfamily members intercellular adhesion molecule 1 and 2 (ICAM-1 and -2) and vascular cell adhesion molecule 1 (VCAM1) (Xiong et al., 2001, 2002; Takagi et al., 2002; Chen et al., 2010a). In response to microbial infection or tissue damage, release of pro-inflammatory mediators increases the blood flow and the expression of endothelial adhesion molecules. This allows leukocytes to increase rolling along the luminal side of the activated endothelium, mediated by weak and transient selectinglycoprotein interactions (McEver, 2002). These interactions can already change the integrin conformation to a more extended one which supports slower leukocyte rolling, as shown for the integrin LFA-1 in neutrophils (Kuwano et al., 2010; Stadtmann et al., 2013). Indeed, binding of P-selectin glycoprotein ligand-1 (PSGL-1) to endothelial selectins leads to activation of Src kinases and Ras-related protein 1 (Rap-1) [see below], supporting slow rolling (Yago et al., 2018). In monocytes, interaction between the $\beta 1$-integrin very late antigen-4 (VLA-4; integrin $\alpha 4 \beta 1$ ) and 


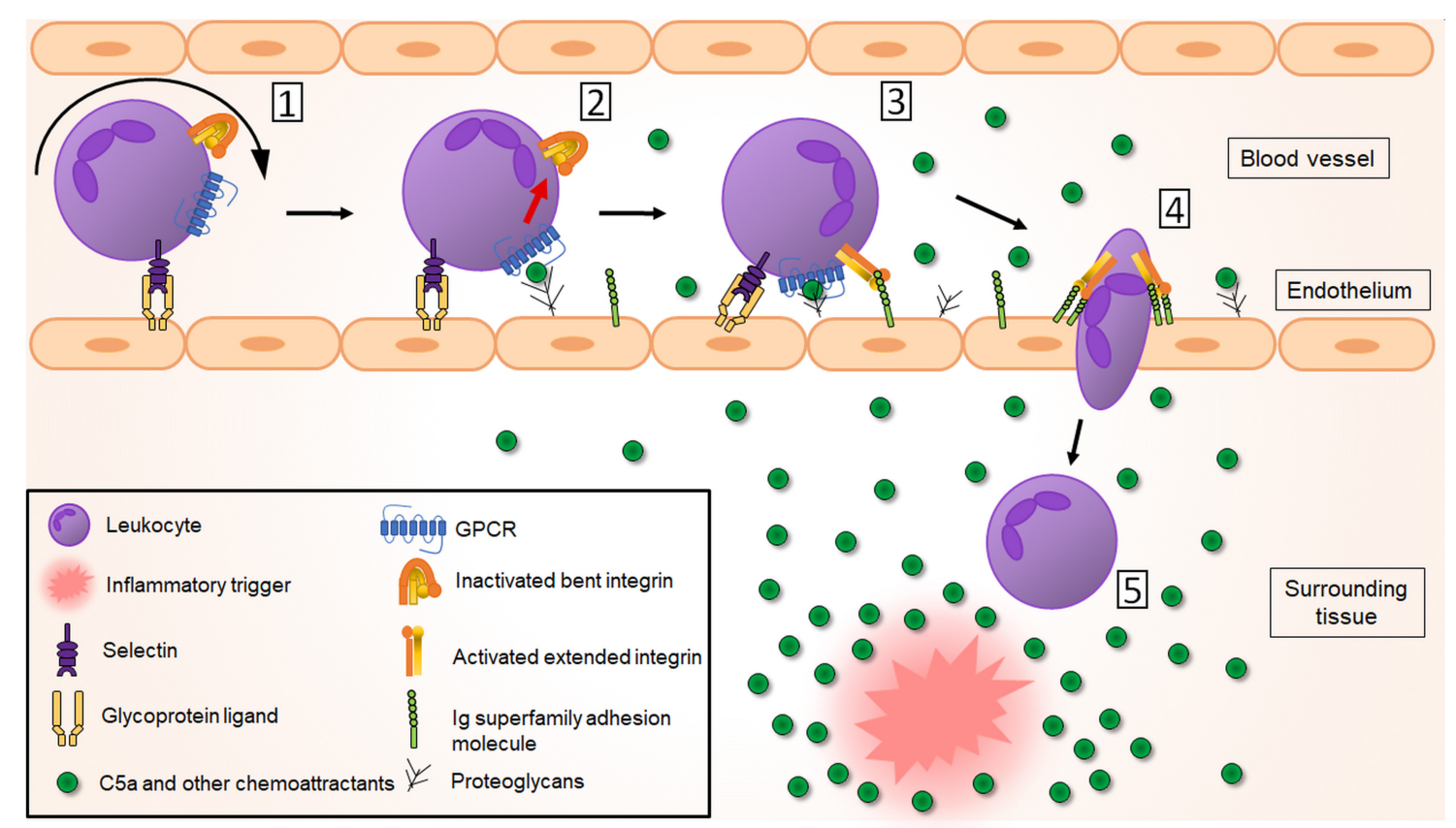

FIGURE 3 | Complement receptors play a crucial role in leukocyte recruitment to the inflammatory site. [1] In response to an inflammatory trigger (infection/tissue damage), leukocytes first roll over the activated endothelium through weak selectin-glycoprotein interactions (for clarity only leukocyte selectins and endothelial glycoproteins are shown here). [2] This allows interaction of leukocyte GPCRs (including C5aR but also other chemoattractant receptors) with chemoattractant molecules, produced by tissue-resident cells in response to and forming a chemotactic gradient toward the inflammatory trigger. This results in inside-out activation of integrins, changing their global conformation from a bent non-activated conformation to an extended, activated conformation with higher affinity for the integrin ligands ICAM-1, ICAM-2 and VCAM-1, which belong to the immunoglobulin (Ig) superfamily adhesion molecules [3]. This leads to a tight adhesion and arrest of the leukocytes to the endothelium. After integrin-mediated crawling to an optimal emigration spot directed by the chemotactic gradient, a transmigratory cup is formed and leukocytes transmigrate [4] through the endothelial barrier and the basement membrane into the surrounding tissue, where their migration will be guided further to the inflammatory site directed by the chemoattractant gradient [5].

VCAM-1 supports transition to slow rolling followed by firm adhesion (Huo et al., 2000).

Due to slow rolling, leukocytes can be activated through interaction with chemokines, C5a, platelet-activating factor (PAF) or LTB4, which are present in the endothelial vicinity or found bound to proteoglycans on the endothelial surface (Middleton et al., 1997; Lefort and Ley, 2012; Miyabe et al., 2017). Leukocyte activation then induces integrin activation via inside-out signaling (also called priming), in which intracellular signals initiated by the GPCR activation are transduced to the cytoplasmic domain and further to the extracellular part of the integrin. A global conformational change in the integrin structure (via a switchblade-like opening) will result in less than a second in an extended, activated, higher affinity state of the integrin. The inside-out signaling process was recently reviewed by Bednarczyk et al. (2020). In short, GPCR-mediated activation of the small GTPase Rap-1 causes it to colocalize with the effector Rap1GTP-interaction adapter molecule (RIAM). RIAM recruits the cytoskeletal protein talin, which is required for the unbending of the two integrin subunits. The N-terminal globular head of talin contains a four-point-one, ezrin, radixin, moesin (FERM) domain that interacts with the conserved NPXY motifs in the $\beta$ cytoplasmic integrin domain, thereby disrupting the $\alpha$ and $\beta$ tail salt bridge to generate the high affinity conformation which enables ligand binding (Calderwood et al., 2002; Campbell and Ginsberg, 2004). Also, the adapter protein Kindlin-3 is able to bind to NPXY motifs and contributes to the full integrin activation (Moser et al., 2008). Eventually, the extended, higher affinity state of the integrin results in a firm adhesion and arrest of the leukocytes to the endothelium (Takagi et al., 2002; Xiao et al., 2004; Nishida et al., 2006). More details on structural rearrangements of integrins is provided by Luo et al. (2007). Due to binding of ligands to the integrins and consequent outsidein signaling, the conformation of the integrin can again slightly change resulting in even higher affinity, further strengthening and stabilizing leukocyte adhesion (Takagi et al., 2002) which has been shown for the interaction between LFA-1 and ICAM1 (CD54) (Chen et al., 2010b). Moreover, Src kinases are involved in sustaining the adhesion of neutrophils through outside-in signaling. Indeed, lack of this outside-in signaling leads to rapid detachment of adherent neutrophils from the endothelium (Giagulli et al., 2006).

Once leukocytes arrest, intraluminal crawling is performed toward optimal emigration sites nearby endothelial cell borders (Massena et al., 2010). In neutrophils, it was shown using intravital microscopy that this crawling mechanism is dependent 
on interaction between CR3 and endothelial ICAM-1 (Diamond et al., 1991; Phillipson et al., 2006) and ICAM-2 (Halai et al., 2014). Of note, binding of LFA-1 to ICAM-1 and VLA-4 to VCAM-1 has also been shown to contribute to neutrophil adhesion (Staunton et al., 1990; Reinhardt et al., 1997; Ding et al., 1999; Phillipson et al., 2006). In monocytes, however, the primary integrin involved in monocyte adhesion and arrest is VLA-4, due to its interaction with VCAM-1 (Hyduk et al., 2007), with a secondary role for LFA-1 and CR3 (Meerschaert and Furie, 1995). In addition, in monocytes both LFA-1 (Auffray et al., 2007) and CR3 are involved in crawling via interactions with ICAM1 and ICAM-2 (Schenkel et al., 2004; Sumagin et al., 2010). In lymphocytes, LFA-1 binding to ICAM-1 on endothelial cells is required for lymphocyte adhesion (Dustin and Springer, 1988), but on stimulated endothelium, also interaction between VLA4 and VCAM-1 was observed (Elices et al., 1990; Vennegoor et al., 1992). The actual crossing of leukocytes through the endothelial layer (diapedesis) into the tissue happens via a transcellular or a paracellular route (Carman and Springer, 2004). Integrins are also involved in this process. To initiate diapedesis, a "transmigratory cup" on the endothelial surface is formed by redistribution of leukocyte integrins LFA-1, CR3 and VLA4. They colocalize with clusters of ICAM-1 and VCAM-1 on endothelial microvilli-like projections at the junctional interface between the adherent leukocyte and the endothelium (Carman and Springer, 2004; Shaw et al., 2004). In neutrophils, also ICAM2 seems to play a role as genetic deletion or blockade of ICAM-2 partially inhibits the neutrophil transmigration process (Huang et al., 2006). ICAM-2 mediates neutrophil transmigration in a stimulus-dependent manner, alongside other adhesion molecules (Woodfin et al., 2009). For more details on transendothelial migration see (Filippi, 2019) and (Gerhardt and Ley, 2015).

Once beyond the endothelial layer, leukocytes still have to cross a discontinuous layer of pericytes, which are long cells surrounding the endothelium and embedded within the basement membrane. The interaction of CR3 and LFA-1 with ICAM-1 on the pericytes is necessary for abluminal crawling of neutrophils, guiding them to gaps (exit points) into the interstitium (Proebstl et al., 2012). This seems to happen specifically at regions poor in extracellular matrix proteins, such as sites low on laminins and collagen IV (Wang et al., 2006). A slightly different process is performed by monocytes. Monocytes were shown to be more deformable, so they do not need to remodel the basement membrane to enlarge these low expression regions, as neutrophils do (Voisin et al., 2009). Using intravital imaging, it has been shown that individual neutrophils, once inside the locally inflamed tissue, can show highly coordinated chemotaxis forming neutrophil clusters ("swarms"). This migration process in extravascular spaces was shown in several mouse models and tissues. "Neutrophil swarming" occurs during infection with bacteria, fungi or parasites, as well as during sterile inflammation (Kienle and Lämmermann, 2016; Lämmermann, 2016). Neutrophil swarming can be of a transient or persistent nature (Chtanova et al., 2008) and its phenotype is influenced by the size of the initial tissue damage, the presence of pathogens, the number of recruited neutrophils and induction of secondary cell death (Kienle and Lämmermann,
2016). Long-distance migration in the neutrophil "swarms" is integrin independent (Lämmermann et al., 2008), but integrin adhesive forces are required to maintain the dense neutrophil clusters. These allow neutrophils to accumulate in the wound center, excluding collagen fibers and making a collagen-free zone. Based on knock out of neutrophil integrins, it was identified that both LFA-1 and CR3 are important to maintain the cell adhesion in the neutrophil "swarm" (Lämmermann et al., 2013).

The role of CR4 (CD11c/CD18) in cellular adhesion is less well characterized. CR4 is closely related to CR3: the entire CR4 $\alpha$-chain (CD11c) shares 63\% sequence homology to the CR3 a-chain (CD11b) (Corbi et al., 1988). Both receptors recognize similar ligands such as $\mathrm{iC} 3 \mathrm{~b}$, fibrinogen and ICAMs and so it was believed they also mediate similar functions. However, expression of CD11c is dominating in monocytederived macrophages (MDMs) and monocyte-derived dendritic cells (MDDCs) where the ratio with CD11b expression is close to $1: 1$. In circulating monocytes, in contrast, CD11c expression is about 7 times lower than CD11b. Functionally, it was shown that CR4 is the main receptor for strong adhesion to the extracellular matrix component fibrinogen. Although CD11b can also bind to fibrinogen, it was shown that blockade of CD11c strongly reduces adhesion strength whereas blockade of CD11b enhances the attachment of MDDCs and MDMs to fibrinogen. Thus, CD11b can have a competitive, negative role in adhesion of MDDCs and MDMs to fibrinogen (Sándor et al., 2016).

Defects in the synthesis of the common $\beta$-chain (CD18) of integrins LFA-1, CR3 or CR4 lead to the rare autosomal-recessive disease leukocyte adhesion deficiency (LAD)-I, characterized by absence or reduced expression of these integrins on leukocytes. As a result, patients have deficiencies in leukocyte adhesion and abnormalities in several adherence-dependent functions like chemotaxis and aggregation. LAD patients are susceptible to recurrent bacterial infections and impaired wound healing, amongst other symptoms, and often die during childhood (Anderson and Springer, 1987; Hogg et al., 1999). A LADI-like phenotype is also seen in LAD-III, another autosomalrecessive disease characterized by mutations in Kindlin-3, which is required in the inside-out signaling and activation of $\beta 2$ integrins (Stepensky et al., 2015). However, LAD-II which yields similar immunodeficiency, is not directly related to integrin functions. Instead, in LAD-II, mutations in a specific GDP-fucose transporter result in impaired synthesis of selectin glycoprotein ligands, impairing the leukocyte rolling and eventually resulting in impaired leukocyte extravasation (Sturla et al., 2001).

\section{ROLE OF COMPLEMENT RECEPTORS IN PHAGOCYTOSIS}

\section{Introduction to Phagocytosis}

Phagocytosis is a cellular process characterized by the recognition and ingestion of particles larger than $0.5 \mu \mathrm{m}$ into a membraneencased vesicle, the phagosome (Nordenfelt and Tapper, 2011; Flannagan et al., 2012). This process contributes to tissue homeostasis and remodeling, and participates in the host defense as it eliminates microorganisms and foreign substances 
(Figure 4). Classical phagocytosis is initiated by the interaction of a particle with specific receptors on the surface of professional phagocytes, more specifically, macrophages and neutrophils. Those receptors include non-opsonic phagocytic receptors, such as Dectin-1 and Mincle that directly recognize conserved PAMPs. Moreover, other receptors recognize host-derived opsonins attached to pathogens, such as complement (e.g., CR3) and Fc gamma receptors ( $\mathrm{Fc} \gamma \mathrm{Rs}$ ), which are extensively studied phagocytic receptors for opsonized particles. Fc $\gamma$ Rs bind the conserved Fc domain of immunoglobulins (Ig), which causes receptor clustering and phosphorylation of immunoreceptor tyrosine-based activation motifs (ITAMs) in the cytoplasmatic tail of the receptor, leading to the recruitment of Syk kinases. This activates various downstream signaling pathways (e.g., ERK, phospholipase D, PKC) mediating cell effector functions such as actin-dependent pseudopod extensions of the plasma membrane around the particle to draw it into the cell (May and Machesky, 2001). In contrast, studies using electron microscopy showed that little to no membrane protrusions were formed during complement-mediated internalization of an opsonized particle, as the particle appeared to "sink" into the cell (Griffin et al., 1975; Kaplan, 1977). The more recent idea, validated by livecell imaging of the entire phagocytic process, is that actinbased membrane protrusions (pseudopods) are formed that surround iC3b-opsonized beads, a mechanism that could have been previously missed during electron microscopy processing
(Hall et al., 2006; Patel and Harrison, 2008; Rotty et al., 2017; Jaumouille et al., 2019). This active, phagocytic cupmediated internalization of the complement-coated particle has become a consensus in the field, replacing the older particle "sinking" model.

Activation of complement receptors leads to signaling pathways and actin cytoskeleton reorganization in such a way that the membrane completely surrounds the target particle, thereby forming the phagosome. The phagocytic cup formation is primed by integrin inside-out signaling induced by Toll-like receptor (TLR) or GPCR stimulation (Freeman and Grinstein, 2014). Talin recruitment induces the high-affinity, extended integrin conformation that enables ligand binding (Calderwood et al., 2002; Campbell and Ginsberg, 2004). Talin also mediates the mechanical coupling of integrins to actin filaments, as forces arising during phagocytosis expose vinculin binding sites on talin (del Rio et al., 2009). This will promote focal adhesion kinase (FAK)-mediated tyrosine phosphorylation of paxillin together with vinculin binding to talin and actin, which serves as a "molecular clutch" that drives phagocytosis (Jaumouille et al., 2019). In turn, integrin "outside-in" signaling will promote actin reorganization to form plasma membrane protrusions. This formation is driven by the Arp $2 / 3$ complex, nucleating actin filaments branches from the sides of pre-existing filaments. The activity of the Arp $2 / 3$ complex is indispensable during complement-mediated phagocytosis, since Arp2/3 inhibition

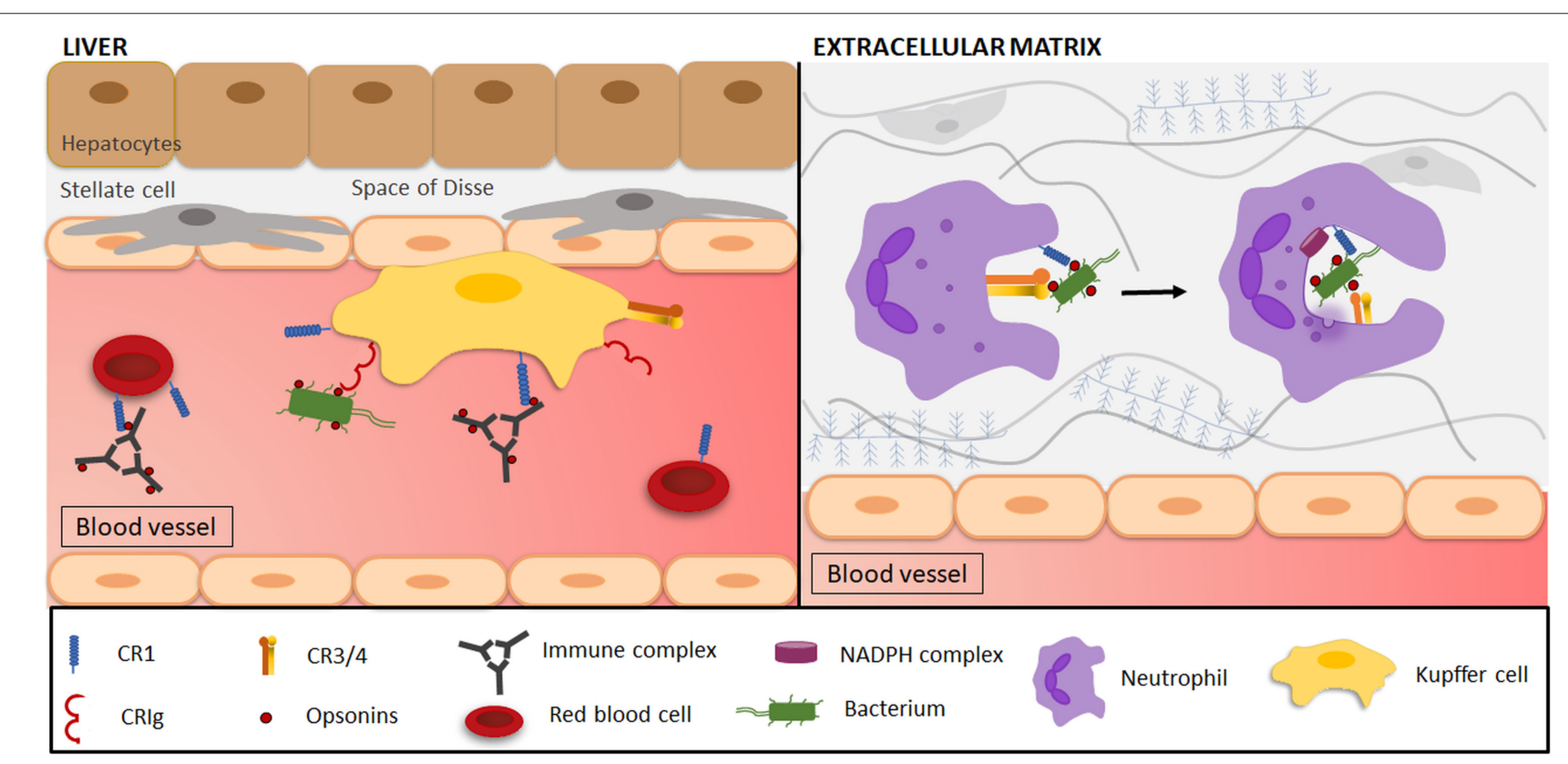

FIGURE 4 | Complement-mediated phagocytosis in the clearance of microorganisms and immune complexes. (Left side) Resident liver macrophages (Kupffer cells/KCs) engulf pathogens, immune complexes and various other particles through interactions with complement receptors. Opsonized (red dots) immune complexes (ICs) are transported to the liver via CR1 on the plasma membrane of circulating red blood cells (RBCs). In the liver, ICs interact with CR1 and scavenger receptors (not shown) on KCs, leading to IC phagocytosis, where after RBCs return to the circulation. Opsonized and free pathogens are recognized by CRIg on KCs and are subsequently engulfed. (Right side) Phagocytes (e.g., neutrophils) are attracted to a site of infection and reach the extracellular matrix by transmigrating across the endothelium. Once there, CR1 on neutrophils will be involved in the attachment of C3-opsonized particles to the cell, after which interaction with CR3 mediates phagocytosis. As the plasma membrane surrounds the target, forming a phagosome, the activation of the nicotinamide adenine dinucleotide phosphate (NADPH) complex and degranulation of neutrophilic granules initiate target degradation. 
with CK-666 inhibits phagocytosis (May et al., 2000; Rotty et al., 2017; Jaumouille et al., 2019). This activity depends on the activation of the GTPase Rho in complement phagocytosis, while GTPases Cdc42 and Rac are required in Fc-mediated phagocytosis (Caron and Hall, 1998). Rho recruits and stimulates the formin $\mathrm{mDia}$, which drives actin protrusions to the particle surface and connects the actin cytoskeleton to microtubules (Palazzo et al., 2001). Active Rho also enables actomyosin contractions by activating the Rho kinase (ROCK), responsible for the increased myosin light chain phosphorylation (Olazabal et al., 2002). Syk kinase activity is required for vinculin recruitment and strengthening of force transmission for optimal particle uptake. Once the target particle is internalized, it combines with early endosomes coming from the endoplasmic reticulum and Golgi apparatus to form the early phagosome. The early phagosome is characterized by the presence of Rab5 and EEA1 proteins at the phagosomal membrane, and does not increase in size, as recycling endosomes are removed from the phagosome and trafficked back to the plasma membrane. Upon phagosome maturation, the fusion with late endosomes modifies the now called late phagosome, which is characterized by the presence of Rab7 and the incorporation of additional copies of the vacuolar-type H+-ATPase (V-ATPase). Finally, lysosomes fuse with the late phagosome to become phagolysosomes which have an acidic $\mathrm{pH}$, and contain hydrolytic enzymes and nicotinamide adenine dinucleotide phosphate (NADPH) oxidase to produce ROS that jointly degrade the ingested particle (Allen and Aderem, 1996).

The importance of complement opsonization in phagocytosis has been demonstrated by a number of studies. C3-deficient mice are immunocompromised and susceptible to lethal bacterial infections. Moreover, clearance of bacteria in the bloodstream by Kupffer cells (KCs) (Helmy et al., 2006) and in the lungs by alveolar macrophages (Neupane et al., 2020) is impaired in C3deficient mice. Other examples include the reduced phagocytic clearance of microorganisms in the presence of serum that has been depleted of complement by heat-inactivation (Scribner and Fahrney, 1976) or treatment with cobra venom factor (Shin et al., 1969). Cobra venom factor has been extensively used in vitro and in vivo: It binds to complement Factor B of the alternative pathway to form a venom factor- $\mathrm{Bb}$ complex that functions as a C3/C5 convertase (Cooper, 1973; von Zabern et al., 1980). This results in the cleavage of C3 and C5, consequently consuming complement components and ultimately leading to the depletion of serum complement activity. The key role of complement opsonization in phagocytosis was also demonstrated by the interference of complement activation by pathogenic virulence factors. In the case of gram-positive S. pneumoniae, the viral capsule inhibits IgG binding and decreases bacterial opsonization with iC3b, preventing phagocytosis by $\mathrm{FcR}$ and complement receptors (Hyams et al., 2010). Also, the E. coli capsule may block complement opsonization by masking surface components (such as LPS) capable of activating the complement pathway (Horwitz and Silverstein, 1980). Impairing complement opsonization of bacteria is not only a defense mechanism that impairs phagocytosis, but also NETosis. In general, complement opsonization has been proven to promote NETosis, as shown by the enhanced NET release by neutrophils in the presence of the serum-opsonized bacteria A. actinomycetemcomitans (Palmer et al., 2016). Yet, this effect was not observed with serumtreated $S$. Aureus, suggesting again that complement-inactivating properties of bacteria might impair effector functions such as phagocytosis and NETosis.

Inherited deficiencies of early classical complement proteins are closely associated with the development of SLE. This systemic autoimmune disease is characterized by antinuclear antibodies, disturbed complement activation and the occurrence of large immunocomplexes (ICs). Homozygous deficiency of $\mathrm{Clq}$ is associated with a 93\% risk of developing SLE. In addition, $75 \%$ of patients with homozygous C4 deficiency develop lupuslike illness (Lewis and Botto, 2006). SLE was observed in $10-30 \%$ of C2-deficient patients, indicating a higher risk of SLE when deficiencies occur in complement proteins of earlier stages of the cascade. How complement deficiency exactly contributes to the development of SLE is not known. One possible mechanism is impairment of complement-mediated immune complex clearance (Figure 4), which leads to the deposition of large non-soluble complexes in tissues. These ICs drive proinflammatory cytokine release and local tissue injury (Davies et al., 1992, 1994). This mechanism is supported by the lower expression of CR1 found on erythrocytes of SLE patients, which is the main receptor involved in IC clearance (Ross et al., 1985). Also, the impaired clearance of apoptotic cells due to complement deficiency might serve as a source of self-antigens to initiate autoimmunity. This is evidenced by the impaired phagocytosis of dead/necrotic cells by macrophages in the absence of C1q (Böttcher et al., 2006; Gullstrand et al., 2009).

\section{Complement Receptor 1 (CR1) Receptor Characterization}

Complement receptor 1 (CR1, CD35, C3b/C4b receptor) is a type 1 membrane bound glycoprotein that specifically interacts with MBL and complement proteins $\mathrm{C} 1 \mathrm{q}, \mathrm{C} 3 \mathrm{~b}, \mathrm{C} 4 \mathrm{~b}$, and with a lower affinity with iC3b (Figure 2 and Table 1) (Nelson, 1953; Gigli and Nelson, 1968; Ghiran et al., 2000). Four polymorphic variants of the receptor exist, the most common one having a molecular mass of approximately $220 \mathrm{kDa}$ and an extracellular domain of 30 tandemly repeating complement control proteins (CCPs), also known as short consensus repeats or sushi domains. The CCP repeats are 59-72 amino acids long, each having four conserved cysteines that form a pattern of disulfide bridges connecting Cys1-Cys3 and Cys2-Cys4 (Reid et al., 1986; Ahearn and Fearon, 1989; Hannan et al., 2005). The CCPs are further grouped into 4 longer homologous repeats (LHR) containing each 7-9 CCPs. There are several binding sites for $\mathrm{C} 3 \mathrm{~b}$ and $\mathrm{C} 4 \mathrm{~b}$ : CCPs 1-3 (LHRA) contains a C4b binding site, whereas CCPs 8-10 (LHR-B) and CCPs 15-17 (LHR-C) contain both C4b and C3b binding sites, although C3b will bind with a higher affinity (Klickstein et al., 1988; Krych et al., 1991). LHR-D is responsible for the binding of two other CR1 ligands, C1q and MBL. CR1 is expressed on erythrocytes, monocytes/macrophages, polymorphonuclear leukocytes, B-lymphocytes, subpopulations of T-lymphocytes, follicular dendritic cells (FDCs) and glomerular podocytes (Fearon, 1980; Reynes et al., 1985; Appay et al., 1990; Rødgaard 
et al., 1991). The soluble form of CR1 (sCR1) is released in the plasma by cell surface proteolytic cleavage of CR1 on leukocytes, and acts together with membrane-bound CR1 as an inhibitor of the classical and alternative complement pathway (Danielsson et al., 1994).

\section{CR1-Mediated Functions}

Protection of host cells against complement activation is mediated by a group of cell surface anchored regulatory proteins, to which CR1 belongs to. CR1 prevents unintended complementmediated injury by decay-accelerating activity of both C3 and C5 convertases and by serving as a co-factor of the serine protease factor I. This promotes factor I-mediated degradation of $\mathrm{C} 3 \mathrm{~b}$ and $\mathrm{C} 4 \mathrm{~b}$, and the cleavage of $\mathrm{iC} 3 \mathrm{~b}$ to $\mathrm{C} 3 \mathrm{c}$ and $\mathrm{C} 3 \mathrm{dg}$ (Iida and Nussenzweig, 1981; Masaki et al., 1992). Besides its regulatory function, CR1 also plays a critical role in the clearance of complement-coated ICs (Figure 4). Formation of ICs by binding of multiple antibodies to antigens leads to $\mathrm{C} 3 \mathrm{~b}$ deposition, causing the opsonized IC to bind to CR1 on erythrocytes. The ICs are subsequently transported to the liver and spleen on the plasma membrane of circulating erythrocytes, where they interact with Fc-receptors and CR1 on macrophages, leading to IC phagocytosis (Cornacoff et al., 1983; Yoshida et al., 1986). After IC delivery, erythrocytes return to the circulation partially lacking CR1 due to proteolytic cleavage during phagocytosis by macrophages, however, CR1 loss on erythrocytes might also be a consequence of erythrocyte maturation (Pascual et al., 1994; Imrie and Jones, 1997; Miot et al., 2002). Ninety-five percent of the CR1 receptors in the peripheral blood circulation are located on erythrocytes, even though the absolute amount of CR1 on erythrocytes is remarkably lower than on neutrophils (950 vs. 57,000 receptors per cell, respectively). However, the high number of circulating erythrocytes makes the clearance of C3bopsonized ICs by erythrocytes 500-1,000 times more likely than by leukocytes (Siegel et al., 1981).

CR1 activity also modulates humoral immunity since it facilitates the retention of antigens to FDCs in the germinal center within secondary lymphoid organs. CR1 on FDCs will capture complement-opsonized immune complexes that carry antigens, which stimulate follicular B-lymphocytes via the Bcell receptor (BCR) (Fang et al., 1998). Deficiency in C3 or depletion of circulating $\mathrm{C} 3$ with cobra venom factor inhibited memory B-lymphocyte formation and showed the indispensable role of C3 opsonization of ICs for appropriate B-lymphocyte function (Klaus and Humphrey, 1977). In addition, a CR1 knockout mouse model showed a reduced amount of activated Blymphocytes in the germinal center and a decreased antibody response (Donius et al., 2013).

In mice, CR1 and CR2 are derived from alternative splicing of the $C r 2$ gene, while in humans they are a product of two distinct but closely linked genes on chromosome 1: CR1 and CR2 [extensively reviewed by (Jacobson and Weis, 2008)]. In addition, CR1 and CR2 expression in mice is limited to B-lymphocytes and FDCs, complicating the use of a mouse model to investigate CR1 functions on myeloid cells. In mice, CR1 still possesses binding sites for $\mathrm{C} 3 \mathrm{~b}$ and $\mathrm{C} 4 \mathrm{~b}$ and serves as a cofactor for $\mathrm{C} 3 \mathrm{~b}$ cleavage by murine factor I, however, its prominent role in phagocytosis and immune adherence is absent (Kinoshita et al., 1985; Molina et al., 1994). Instead, CR1 on FDCs enhances the retention of antigens on their surface to generate an appropriate antibody response by activated B-lymphocytes of the germinal center, as discussed above (Donius et al., 2013). Interestingly, rodents carry the Cr1-related protein Y (Crry) gene, from which the human CR1 gene has evolved, encoding a membrane-bound complement regulatory protein that is expressed in almost every cell type. Thus, it explains the high degree of protein sequence similarity with human CR1, which is translated to a similar effector function, since it also accelerates the decay of $\mathrm{C} 3 / \mathrm{C} 5$ convertases and acts as a cofactor for factor I-mediated cleavage of C3b and C4b (Kim et al., 1995). However, the involvement in phagocytosis and adhesion has not been demonstrated yet for Crry, indicating that the mouse homolog for CR1's immune adherence and phagocytosis roles is still unidentified.

The limited research into the phagocytic role of human CR1 has mostly been conducted in the 1980s. The adhesive and phagocytic function of CR1 were mainly assessed through rosette or cluster formation of immunoglobulin and complementcoated sheep erythrocytes to polymorphonuclear leukocytes, monocytes and macrophages, and their subsequent ingestion. The phagocytosis of $\mathrm{C} 3 \mathrm{~b} / \mathrm{C} 4 \mathrm{~b}$-opsonized particles occurs in synergy with CR1 and Fc-receptors on both human and murine neutrophils and macrophages (Mantovani, 1975; Ehlenberger and Nussenzweig, 1977). CR1 is primarily involved in the attachment of $\mathrm{C} 3 \mathrm{~b}$-opsonized particles to the cell as shown by the impaired attachment of C3b-coated erythrocytes after antiCR1 treatment (Newman et al., 1985), whereafter interaction with the Fc-receptors or CR3 mediates phagocytosis (Figure 4) (Fällman et al., 1993). C3 opsonization by itself is not able to trigger CR1-mediated phagocytosis, therefore the presence of IgG complexes is essential to stimulate particle ingestion through its Fc fragments (Newman et al., 1984). CR1 phagocytosis is only mediated after receptor transition from a resting state, in which it binds ligand-coated particles, to an activated state. Even though the biochemical events that account for the shift in activity are unknown, an important role for CR1 phosphorylation has been suggested as PKC stimulation with phorbol myristate acetate (PMA) and PAF enabled phagocytic function by CR1 (Changelian and Fearon, 1986; Bussolino et al., 1989). Likewise, the signaling pathway used by activated CR1 to mediate its effector functions has not yet been characterized.

\section{Complement Receptor of the Immunoglobulin Family (CRIg) Receptor Characterization}

In 2000, a novel human Z39Ig gene on chromosome X was reported, encoding a new member of the immunoglobulin superfamily (Langnaese et al., 2000). A few years later, the complement receptor of the immunoglobulin family (CRIg), also referred to as V-set and Ig domain (VSIG4)/B7 family-related protein or Z39Ig, was identified as a receptor expressed on tissue resident and sinusoidal macrophages, especially hepatic KCs, and more recently also on human monocyte derived dendritic cells (Table 1) (Helmy et al., 2006; Munawara et al., 2019). 
CRIg is a type 1 transmembrane receptor with two alternatively spliced variants in humans: long huCRIg(L) and short huCRIg(S) (Figure 2). The latter consists only of an extracellular variable (Vtype) Ig domain, while huCRIg(L) also contains a constant (C2type) Ig domain. Mice express only one form of muCRIg with a single Ig V-type domain and therefore resembles the shorter human splice variant.

\section{CRIg-Mediated Functions}

CRIg binds to the beta chain of $\mathrm{C} 3 \mathrm{~b}$, to $\mathrm{iC} 3 \mathrm{~b}$ and $\mathrm{C} 3 \mathrm{c}$, and this receptor is required for the binding and phagocytosis of opsonized pathogens from the circulation, thereby limiting systemic bacteremia or parasitemia (Wiesmann et al., 2006). This has been shown by the reduced capture and elimination of S. aureus and L. monocytogenes by the liver KCs in CRIg knock-out mice compared to wild-type mice (Helmy et al., 2006). Also, complement opsonization of parasites has been shown to be indispensable for capture and clearance via CRIg by KCs (Liu et al., 2016). However, other investigators observed that complement depletion did not affect the capture of gram-positive bacteria, suggesting that CRIg may bind microorganisms directly in a complement-independent manner (Zeng et al., 2016). This led to the discovery that CRIg functions as a pattern recognition receptor that recognizes gram-positive bacteria via lipoteichoic acid binding in vitro. Nevertheless, whether this occurs under high shear forces in vivo was questionable (Zeng et al., 2016). Moreover, un-opsonized gram-negative bacteria also displayed an efficient clearance, which cannot be explained by the direct recognition of lipoteichoic acid (Broadley et al., 2016). Therefore, a "dual track clearance" mechanism consisting of parallel "fast" and "slow" clearance of circulating bacteria has been described (Broadley et al., 2016). Circulating bacteria (opsonized or not) are rapidly cleared by the liver KCs via CRIg and scavenger receptors, whereas the slower process of complement opsonization enables a second clearance step via platelet binding and phagocytosis by KCs, also using CRIg. Even though the liver captures and kills $>90 \%$ of all circulating pathogens, a shift toward spleen clearance has been observed with growing particle size. This mechanism adds another layer to the efficient and fast clearance of circulating bacteria by the liver and spleen. Interestingly, CRIg has also been found to be a negative regulator of T-lymphocyte responses in tissues. CRIg can function as a coinhibitory molecule of the B7/CD28 superfamily, suppressing T-lymphocyte proliferation and cytokine production, thereby maintaining peripheral $\mathrm{T}$ lymphocyte tolerance in healthy tissues (Vogt et al., 2006; Yuan et al., 2017; Munawara et al., 2019). Interestingly, this inhibitory function is regulated by CRIg internalization when bound to C3b or iC3b (e.g., opsonized target), allowing an adequate Tlymphocyte response to progress during tissue inflammation (Fearon et al., 1981; Sengeløv et al., 1994).

Murine KCs express CRIg and CR3 on the plasma membrane, while human KCs additionally express CR1 and CR4. However, none of these receptors on KCs are more involved in pathogen clearance than CRIg. The relationship between CRIg and CR3 was investigated in mice. Even though both receptors are expressed on KCs and share a common ligand, distinct modes of pathogen clearance have been observed. CRIg binds and internalizes opsonized pathogens independently of receptor crosslinking, additional activation stimuli or the presence of divalent cations, which are all indispensable requirements for CR3-mediated phagocytosis (Gorgani et al., 2008). Thus, CR3 contributes rather indirectly to pathogen clearance by the recruitment of neutrophils through their interaction with ICAM1 (Gregory et al., 2002). The subcellular localization and intracellular trafficking of CRIg also differs from CR3: CRIg is mostly expressed on recycling endosomes where they aid in delivering membrane to the forming phagosome and ensure a sufficient supply of CRIg to the plasma membrane to mediate CRIg-dependent internalization (Helmy et al., 2006). In contrast, CR3 is located in secretory vesicles that fuse with the plasma membrane upon cytokine stimulation. CRIg is not degraded after particle internalization, instead, CRIg is recycled to the endosome pool prior or during phagosome-lysosome fusion. The signaling mechanism induced by CRIg activation is not known. CR3 and CRIg potentially share some intracellular mediators of the CR3 signaling pathway, as they are co-expressed on macrophages and share a common ligand, however, more studies are needed to clarify this.

The ability of CRIg to bind to the beta chain subunit of $\mathrm{C} 3 \mathrm{~b}$ abrogates the interaction of $\mathrm{C} 3$ and $\mathrm{C} 5$ convertases of the alternative pathway (Wiesmann et al., 2006). The potential immune regulatory role of CRIg has further been investigated and led to the development of a soluble CRIg-Fc fusion protein with enhanced complement inhibitory efficacy. Because CRIg only blocks complement activation of the alternative pathway, and not the classical or lectin pathway, the novel CRIgFc complement inhibitor was thought to have an effect on the progression of diseases in which the alternative pathway contributes greatly. Its benefits were confirmed in mouse models of arthritis, where CRIg-Fc injection caused a reduction of inflammation and bone loss compared to control mice, even when the disease was already established (Katschke et al., 2007). Also, lupus-prone MRL lymphoproliferation (MRL/lpr) mice showed significantly less skin lesions, proteinuria and kidney pathology when treated with CRIg-Fc (Lieberman et al., 2015), and it prevented local and remote tissue injury induced by ischemia-reperfusion (Chen et al., 2011). A novel CRIg/FH fusion protein, combining the extracellular domain of CRIg and the functional domain of factor $\mathrm{H}$, was designed to inhibit both the classical and alternative complement pathway and displayed similar effects in ischemia-reperfusion injury and lupus nephritis (Qiao et al., 2018; Hu et al., 2019; Shi et al., 2019). All together, these results indicate the potential effective role of soluble CRIg proteins in clinical settings of intestinal and renal ischemiareperfusion injury, SLE, inflammatory arthritis, autoimmune liver disease (Jung et al., 2012) and potentially other diseases in which the alternative pathway is involved.

\section{Complement Receptor 2 (CR2) Receptor Characterization}

CR2 (CD21) is a $145 \mathrm{kDa}$ type 1 membrane bound glycoprotein that comprises 15-16 CCPs (depending on the alternative splicing of one exon), a transmembrane domain and a short 34 amino acid cytoplasmic tail (Figure 2) (Hannan et al., 2002). 
The receptor structure closely resembles CR1, but lacks a few $\mathrm{N}$-terminal CCP repeats that are known to bind $\mathrm{C} 3 \mathrm{~b} / \mathrm{C} 4 \mathrm{~b}$. Instead, CR2 binds the ligands $\mathrm{iC} 3 \mathrm{~b}, \mathrm{C} 3 \mathrm{dg}$, and C3d (Molina et al., 1994). In humans, CR2 binds the gp350/220 viral envelope protein of the Epstein-Barr virus (EBV) (Fingeroth et al., 1984), the immunoregulatory protein CD23 (Aubry et al., 1992) and interferon-alpha (Asokan et al., 2006). Szakonyi et al. provided substantial information on the structure of CR2 by determining the crystal structure of CCP1 and CCP2 in complex with C3d at $2.0 \AA$ (Szakonyi et al., 2001). Human CR2 is expressed primarily on mature B-lymphocytes and FDCs, although a subset of peripheral and thymic Tlymphocytes and epithelial cells also express the receptor (Table 1).

\section{CR2-Mediated Functions}

CR2 exerts distinct functions depending on ligand binding: (1) On B-lymphocytes, CR2 promotes antigen receptor-mediated signal transduction by the formation of a B-lymphocyte coreceptor complex with the signaling protein CD19 and the tetraspanin CD81. Co-ligation of the B-cell receptor with CR2-CD19-CD81 complexes by C3d-coated antigens/immune complexes can significantly amplify signaling in B-lymphocytes and lower the threshold for B-lymphocyte activation by at least two orders of magnitude (Carter and Fearon, 1992). (2) On FDCs, CR2 mediates the retention of C3-coated antigens, presumably to enhance interactions with B-lymphocytes of the germinal center (Reynes et al., 1985). (3) As a receptor for $\mathrm{CD} 23$, one of the main functions of CR2 is the promotion of $\mathrm{B}$ lymphocyte class switching and the increased production of $\operatorname{IgE}$ (Aubry et al., 1992). (4) EBV hijacks CR2 for B-cell infection; binding to CR2 initiates the entry of the virus in B-lymphocytes (Tanner et al., 1987).

CR2 is not directly implicated in adhesion or phagocytosis. However, there are indications that CR2 contributes to the pathogenesis of SLE. In patients with SLE, the expression of CR1 and CR2 on B-lymphocytes is decreased by $50 \%$ and a CR2 variant with three single nucleotide polymorphisms (SNPs) was associated with a 1.54 increased risk of SLE (Wilson et al., 1986; Wu et al., 2007). However, whether CR2 defects are the consequence or the drivers of the disease is not completely clear. In the mouse model of SLE (MRL/lpr), reduced expression of CR1 and CR2 occurred on B-lymphocytes before the clinical signs of SLE appear (Takahashi et al., 1997). Also, SNPs in the $\mathrm{Cr} 2$ gene are sufficient for mice to develop an SLE-like disease (Boackle et al., 2001). Moreover, increased serum levels of antinuclear Abs and anti-DNA Abs have been found in $\mathrm{Cr} 2^{\text {null }}$ mice ( $\mathrm{Wu}$ et al., 2002). These results indicate a role for CR2 in SLE pathogenesis, however, one must keep in mind that these were obtained in mice, in which a single gene encodes for both CR1 and CR2. Human CR2 has been shown to bind DNA and chromatin in the absence of $\mathrm{C} 3$ opsonization, therefore, CR2 deficiency in SLE might also influence the development of autoimmunity in SLE through altered receptor interactions with DNA (Asokan et al., 2013).

\section{Complement Receptors CR3 and CR4 CR3 and CR4-Mediated Functions}

Out of all complement receptors, CR3 (CD11b/CD18) is the most widely expressed and a highly versatile receptor. It is expressed by macrophages, monocytes, neutrophils, dendritic cells, NK cells and activated lymphocytes (Table 1) (Ho and Springer, 1982; Ross and Vetvicka, 1993). The importance of CR3 is highlighted by its contribution to both the recruitment of leukocytes (via adhesion) and phagocytosis of targets. CR4, which contains the CD11c $\alpha$-chain instead, is highly expressed in monocytes, macrophages and DCs, where it mediates similar functions to CR3 (Torres-Gomez et al., 2020a). For a detailed description of CR3 and CR4 structure and motifs, see section $\beta 2$-Integrin Family Complement Receptors CR3 and CR4.

CR3 and CR4 interact predominantly with iC3b to promote phagocytosis, a fragment that is generated from factor Idependent cleavage of C3b (Beller et al., 1982; Keizer et al., 1987). In general, presence of iC3b-opsonized particles is not sufficient to induce CR3-mediated phagocytosis. CR3 requires inside-out activation which includes a receptor conformational change into the high-affinity "extended" and "open" state $\left(\mathrm{E}^{+} \mathrm{H}^{+}\right)$ and receptor clustering in the membrane, together resulting in efficiently binding and internalizing iC3b-opsonized particles. Integrin clustering has been found to be indispensable for ligand binding and receptor signaling, with $\mathrm{Fc} \gamma \mathrm{R}$ stimulation promoting CR3 aggregation in phagocytic cups by enhancing the receptor's lateral mobility (Jongstra-Bilen et al., 2003). Also, ligand binding to CR3 was enhanced in neutrophils with increased receptor clustering after PMA stimulation, with loss of clustering correlating with a loss in receptor activity (Detmers et al., 1987). The stimuli for inside-out signaling include inflammatory cytokines (TNF- $\alpha$ ), chemokines, Nformylmethionine-leucyl-phenylalanine (fMLP), TLR agonists and adhesion to extracellular matrix (laminin, fibronectin) (Sampson et al., 1991). These lead to inside-out activation via the Rap1-RIAM-Talin pathway. Genetic ablation of these proteins leads to defects in complement-mediated phagocytosis, as illustrated by impaired adhesion, phagocytosis and ROS production by RIAM-deficient phagocytes in vitro, and signs of LAD in RIAM knockout mice in vivo (Klapproth et al., 2015; Torres-Gomez et al., 2020b). Inside-out signaling drives the phosphorylation of CD18 on serine residues, but not of the alpha chains (CD11b or CD11c), which are constitutively phosphorylated (Chatila et al., 1989; Fagerholm et al., 2006). These phosphorylations, although originating differently, are both required for CR3- and CR4-mediated leukocyte adhesion and phagocytosis.

Ligand binding initiates a phagocytic signal that promotes particle internalization via a signaling pathway that relies on well-defined molecular players, described in detail in section Introduction to Phagocytosis. It requires Arp2/3 and mDia-mediated actin polymerization, and Rho activity. Actin polymerization that drives the phagosomal cup expansion is coupled to integrins via the activity of tyrosine kinases (e.g., Src and Syk) and binding to talin and vinculin which create anchoring points for the force transmission from actin 
polymerization (Jaumouille et al., 2019). Besides iC3b, a wide range of unrelated ligands are also capable of interacting with CR3, including but not limited to fibrinogen, factor X, neutrophil inhibitory factor (NIF), collagen, denatured proteins and plastics (Yakubenko et al., 2002). Studies with inhibitory mAbs directed to multiple regions of this receptor showed that the I domain of CR3 contains multiple overlapping ligand binding sites which are responsible for the receptor's broad ligand specificity (Diamond et al., 1993). Within this domain, three amino acids $\left(\mathrm{Phe}^{246}\right.$, $\left.\mathrm{Asp}^{254}, \mathrm{Pro}^{257}\right)$ were identified as critical for CR3dependent ligand binding (Yakubenko et al., 2002). Although CR3 and CR4 interact with a number of unrelated ligands with no clear receptor consensus motif, the MIDAS of the I domain is apparently a common ligand recognition site for both receptors (Vorup-Jensen and Jensen, 2018). In addition to the I domain, a unique lectin domain, located C-terminally to the I domain, participates in the binding of microbial carbohydrates (e.g., beta-glucan) (Ross et al., 1987). The binding of cell wall carbohydrates to the lectin domain serves as an additional signal to mediate phagocytosis of iC3b-opsonized fungi (Cain et al., 1987). In addition, the lectin domain has been shown to be responsible for the non-opsonized phagocytosis properties of CR3, as demonstrated by the phagocytosis of non-opsonized zymosan (Le Cabec et al., 2002).

Although CR3 and CR4 share a high degree of homology, functional differences between these receptors are becoming progressively clearer. For instance, CR3 and CR4 bind iC3b differently (Xu et al., 2017). CR3 binds iC3b at two separate sites, which are distinct from the two iC3b-binding sites found in CR4. Moreover, CR3 has generally more affinity toward positivelycharged ligands, such as major basic protein in the brain and the antimicrobial peptide LL-37. On the other hand, CR4 binds well to heparin and osteopontin, both highly negative molecules (Vorup-Jensen and Jensen, 2018). CR3 and CR4 may also differ in which function they perform preferentially in cells. Studies in vitro suggested CR3 as the main phagocytic receptor for iC3bopsonized bacteria, whereas CR4 predominated as an adhesion molecule for monocytic cells (Erdei et al., 2019). In alveolar macrophages, CR3 mediated the majority of the attachment to C3-opsonized sheep erythrocytes, whereas CR4, although more abundant, had a minor role. That disparity was correlated to differences in plasma membrane motility of CR3 and CR4, with CR4 being less mobile (Ross et al., 1992). Also, there is only $56 \%$ homology between the cytoplasmic tail of CR3 $\alpha$ and CR $4 \alpha$, indicating cytoplasmatic structural differences that might affect the binding of signaling molecules, possibly contributing to some distinct receptor functional properties (Ross et al., 1992).

Deficiencies in CR3 and CR4 recapitulate in many ways the deficiency of complement components, such as in the susceptibility to recurrent infections (Rosetti and Mayadas, 2016). These are of particular importance in CR3 and CR4 since the receptors not only control phagocytosis of opsonized material, but of unrelated ligands and also mediate the recruitment of leukocytes. CD11b deficiency leads to more severe sepsis and larger bacterial load in a model of murine cecal-ligation and puncture (Liu et al., 2014). Similarly, mice infected with S. aureus (Flick et al., 2004) or S. pneumoniae (Prince et al., 2001) have increased bacteremia and mortality when lacking a functional CR3. Deficiency in CD18 causes LAD-I, characterized by frequent life-threatening infections, elevated neutrophil numbers in the bloodstream, and impaired wound healing. Patients with LAD-I-related mutations in CD18 present reduced expression of CR3 and functional defects, such as low binding to iC3b, bovine serum albumin and fibrinogen (Hogg et al., 1999; Mathew et al., 2000). Some unexpected aspects of infection are also revealed in the absence of CR3 and CR4. Phagocytosis of the pathogen C. neoformans requires complement receptors, although it does not require complement opsonization (Taborda and Casadevall, 2002). Antibody mediated blockade of CR3 and CR4, or deficiency in CD18 impaired macrophage phagocytosis of the yeast significantly, which was triggered by glucuronoxylomannan molecules exposed at the yeast capsule. Moreover, the gram-negative bacteria $F$. tularensis subvert the complement system to foster bacterial survival. $F$. tularensis is phagocytosed by DCs in a C3-, CR3-, and CR4dependent manner, however, this internalization mechanism stimulates proinflammatory cytokine production, intracellular bacterial growth and DC death instead (Ben Nasr et al., 2006).

Complement is also involved in the clearance of dead cells. C3 opsonization and CR3 are required for the clearance of apoptotic Jurkat cells by macrophages in vitro. Antibody blockade of C3 or CR3 was able to inhibit apoptotic cell clearance significantly, whereas CR4 blockade had a partial effect (Takizawa et al., 1996). An interesting observation by Mevorach et al. was that addition of serum to assays of apoptotic cell phagocytosis increased the uptake efficiency several fold (Mevorach et al., 1998). In this study, complement deposition was induced, among other factors, by exposed phosphatidylserine in apoptotic cells. Interestingly, it was shown that transfection of $\mathrm{CHO}$ cells with $\mathrm{CR} 3$ alone is sufficient to promote phagocytosis of apoptotic bodies by $\mathrm{CHO}$ cells. More recently, numerous studies implicated CR3 and CR4 also in the clearance of necrotic cells (Gaipl et al., 2001; Gullstrand et al., 2009). It was shown that complement factors C1q and C3 bound preferentially to necrotic cells over apoptotic cells in vitro, which drove their phagocytosis by macrophages. In addition, CR3 and CR4 present a variety of scavenging functions that are independent of opsonization, such as its binding to nucleic acids, glycosaminoglycans and denatured proteins (Vorup-Jensen and Jensen, 2018). Both receptors, but especially CR3, are hypothesized to assist in the prevention of autoimmunity and inflammation by promoting debris clearance. In line with this, genome-wide association studies have identified 3 SNPs that are strongly associated with the development of SLE (Nath et al., 2008; Faridi et al., 2017). These SNPs are located in the ITGAM gene and result in a variety of dysfunctions of CD11b, including reduced integrin activation, leukocyte adhesion, ligand binding and phagocytosis. Moreover, the defective CD11b variants cause an excessive production of type I interferon, which drives SLE development and severity (Faridi et al., 2017). 


\section{CONCLUSION}

In this review, the role of complement and complement receptors in the regulation of immunity and inflammation was discussed, with a focus on their function in leukocyte recruitment and phagocytosis in several tissues. Activation of complement anaphylatoxin receptors $\mathrm{C} 3 \mathrm{aR}$ and $\mathrm{C} 5 \mathrm{aR}$ mainly mediates chemotaxis of leukocytes to inflammatory sites for pathogen clearance or tissue regeneration. C5L2 is additionally involved in regulation of $\mathrm{C} 5 \mathrm{aR}$ signaling, by exerting both immune suppressive as immune activating functions. Activation of anaphylatoxin- and other GPCRs during rolling is essential for further leukocyte transmigration into inflamed tissues, which is mediated by activation of CR3, CR4 and other integrins. After extension by inside-out and outside-in signaling, they participate in firm endothelial adhesion, diapedesis and leukocyte chemotaxis toward the inflammatory trigger. Within tissues, activated CR3 and CR4 are involved in phagocytosis by mainly interacting with iC3b-opsonized pathogens. Moreover, complement receptors CR1, CRIg and CR2 are interacting with several components of the complement cascade, as such contributing to complement-mediated phagocytosis and celltype specific immune regulatory roles. The importance of a correctly functioning complement system is highlighted by diseases such as LAD and SLE, which are characterized by deficiencies in leukocyte extravasation and phagocytosis due to impaired complement molecules. Differences in complement

\section{REFERENCES}

Ahearn, J. M., and Fearon, D. T. (1989). Structure and function of the complement receptors, CR1 (CD35) and CR2 (CD21). Adv. Immunol. 46, 183-219. doi: 10.1016/S0065-2776(08)60654-9

Allen, L. A., and Aderem, A. (1996). Mechanisms of phagocytosis. Curr. Opin. Immunol. 8, 36-40. doi: 10.1016/S0952-7915(96)80102-6

Ames, R. S., Li, Y., Sarau, H. M., Nuthulaganti, P., Foley, J. J., Ellis, C., et al. (1996). Molecular cloning and characterization of the human anaphylatoxin C3a receptor. J. Biol. Chem. 271, 20231-20234. doi: 10.1074/jbc.271.34.20231

Anderson, D. C., and Springer, T. A. (1987). Leukocyte adhesion deficiency: an inherited defect in the Mac-1, LFA-1, and p150,95 glycoproteins. Аnnu. Rev. Med. 38, 175-194. doi: 10.1146/annurev.me.38.020187. 001135

Appay, M. D., Kazatchkine, M. D., Levi-Strauss, M., Hinglais, N., and Bariety, J. (1990). Expression of CR1 (CD35) mRNA in podocytes from adult and fetal human kidneys. Kidney Int. 38, 289-293. doi: 10.1038/ki.1990.198

Asokan, R., Banda, N. K., Szakonyi, G., Chen, X. S., and Holers, V. M. (2013). Human complement receptor 2 (CR2/CD21) as a receptor for DNA: implications for its roles in the immune response and the pathogenesis of systemic lupus erythematosus (SLE). Mol. Immunol. 53, 99-110. doi: 10.1016/j.molimm.2012.07.002

Asokan, R., Hua, J., Young, K. A., Gould, H. J., Hannan, J. P., Kraus, D. M., et al. (2006). Characterization of human complement receptor type 2 (CR2/CD21) as a receptor for IFN-alpha: a potential role in systemic lupus erythematosus. J. Immunol. 177, 383-394. doi: 10.4049/jimmunol.177.1.383

Aubry, J. P., Pochon, S., Graber, P., Jansen, K. U., and Bonnefoy, J. Y. (1992). $\mathrm{CD} 21$ is a ligand for CD23 and regulates IgE production. Nature 358, 505-507. doi: $10.1038 / 358505 \mathrm{a} 0$

Auffray, C., Fogg, D., Garfa, M., Elain, G., Join-Lambert, O., Kayal, S., et al. (2007). Monitoring of blood vessels and tissues by a population of monocytes with patrolling behavior. Science 317, 666-670. doi: 10.1126/science.1142883 proteins between mice and men and the differences in cells that express specific complement receptors in both species do not facilitate research on molecular pathways and partially explain remaining knowledge gaps. Examples are our lack of understanding on the mechanisms that allow CR3 to either stimulate phagocytosis or cell migration depending on the type of ligand bound. Novel therapies targeting the complement system have great beneficial potential in a number of kidney, brain and articular diseases, highlighting the significance of further research on complement receptor function and regulation.

\section{AUTHOR CONTRIBUTIONS}

SV, SC, and PM wrote the manuscript and prepared the figures. PP and PM provided critical input and corrected the manuscript. All authors contributed to the article and approved the submitted version.

\section{FUNDING}

This work was supported by the Research Foundation Flanders (FWO-Vlaanderen projects G080818N and G058421N), a C1 grant $(\mathrm{C} 16 / 17 / 010)$ from KU Leuven and the Rega Foundation. SV and SC obtained FWO-SB (1S56521N) and FWO-FR Ph.D. (11A4220N) fellowships, respectively. PM is a beneficiary of the Marie Skłodowska-Curie fellowship (MSCA-IF-2018-839632).

Bamberg, C. E., Mackay, C. R., Lee, H., Zahra, D., Jackson, J., Lim, Y. S., et al. (2010). The C5a receptor (C5aR) C5L2 is a modulator of C5aR-mediated signal transduction. J. Biol. Chem. 285, 7633-7644. doi: 10.1074/jbc.M109.092106

Barnum, S. R. (2015). C4a: an anaphylatoxin in name only. J. Innate Immun. 7, 333-339. doi: 10.1159/000371423

Bednarczyk, M., Stege, H., Grabbe, S., and Bros, M. (2020). $\beta 2$ integrins-multifunctional leukocyte receptors in health and disease. Int. J. Mol. Sci. 21:1402. doi: $10.3390 /$ ijms 21041402

Beller, D. I., Springer, T. A., and Schreiber, R. D. (1982). Anti-Mac-1 selectively inhibits the mouse and human type three complement receptor. J. Exp. Med. 156, 1000-1009. doi: 10.1084/jem.156.4.1000

Ben Nasr, A., Haithcoat, J., Masterson, J. E., Gunn, J. S., Eaves-Pyles, T., and Klimpel, G. R. (2006). Critical role for serum opsonins and complement receptors $\mathrm{CR} 3(\mathrm{CD} 11 \mathrm{~b} / \mathrm{CD} 18)$ and $\mathrm{CR} 4(\mathrm{CD} 11 \mathrm{c} / \mathrm{CD} 18)$ in phagocytosis of Francisella tularensis by human dendritic cells (DC): uptake of Francisella leads to activation of immature DC and intracellular survival of the bacteria. J. Leukoc. Biol. 80, 774-786. doi: 10.1189/jlb.1205755

Bénard, M., Raoult, E., Vaudry, D., Leprince, J., Falluel-Morel, A., Gonzalez, B. J., et al. (2008). Role of complement anaphylatoxin receptors (C3aR, C5aR) in the development of the rat cerebellum. Mol. Immunol. 45, 3767-3774. doi: 10.1016/j.molimm.2008.05.027

Biglarnia, A. R., Huber-Lang, M., Mohlin, C., Ekdahl, K. N., and Nilsson, B. (2018). The multifaceted role of complement in kidney transplantation. Nat. Rev. Nephrol. 14, 767-781. doi: 10.1038/s41581-018-0071-x

Boackle, S. A., Holers, V. M., Chen, X., Szakonyi, G., Karp, D. R., Wakeland, E. K., et al. (2001). Cr2, a candidate gene in the murine Sle1c lupus susceptibility locus, encodes a dysfunctional protein. Immunity 15, 775-785. doi: 10.1016/S1074-7613(01)00228-X

Böttcher, A., Gaipl, U. S., Fürnrohr, B. G., Herrmann, M., Girkontaite, I., Kalden, J. R., et al. (2006). Involvement of phosphatidylserine, alphavbeta3, CD14, CD36, and complement $\mathrm{Clq}$ in the phagocytosis of primary necrotic lymphocytes by macrophages. Arthritis Rheum. 54, 927-938. doi: 10.1002/art.21660 
Brennan, F. H., Lee, J. D., Ruitenberg, M. J., and Woodruff, T. M. (2016). Therapeutic targeting of complement to modify disease course and improve outcomes in neurological conditions. Semin. Immunol. 28, 292-308. doi: 10.1016/j.smim.2016.03.015

Broadley, S. P., Plaumann, A., Coletti, R., Lehmann, C., Wanisch, A., Seidlmeier, A., et al. (2016). Dual-track clearance of circulating bacteria balances rapid restoration of blood sterility with induction of adaptive immunity. Cell Host Microbe 20, 36-48. doi: 10.1016/j.chom.2016.05.023

Bussolino, F., Fischer, E., Turrini, F., Kazatchkine, M. D., and Arese, P. (1989). Platelet-activating factor enhances complement-dependent phagocytosis of diamide-treated erythrocytes by human monocytes through activation of protein kinase $\mathrm{C}$ and phosphorylation of complement receptor type one (CR1). J. Biol. Chem. 264, 21711-21719. doi: 10.1016/S0021-9258(20)88244-1

Cain, J. A., Newman, S. L., and Ross, G. D. (1987). Role of complement receptor type three and serum opsonins in the neutrophil response to yeast. Complement 4, 75-86. doi: 10.1159/000463011

Calderwood, D. A., Yan, B., de Pereda, J. M., Alvarez, B. G., Fujioka, Y., Liddington, R. C., et al. (2002). The phosphotyrosine binding-like domain of talin activates integrins. J. Biol. Chem. 277, 21749-21758. doi: 10.1074/jbc.M111996200

Campbell, I. D., and Ginsberg, M. H. (2004). The talin-tail interaction places integrin activation on FERM ground. Trends Biochem. Sci. 29, 429-435. doi: 10.1016/j.tibs.2004.06.005

Caporale, L. H., Tippett, P. S., Erickson, B. W., and Hugli, T. E. (1980). The active site of C3a anaphylatoxin. J. Biol. Chem. 255, 10758-10763. doi: 10.1016/S0021-9258(19)70372-X

Carman, C. V., and Springer, T. A. (2004). A transmigratory cup in leukocyte diapedesis both through individual vascular endothelial cells and between them. J. Cell Biol. 167, 377-388. doi: 10.1083/jcb.200404129

Caron, E., and Hall, A. (1998). Identification of two distinct mechanisms of phagocytosis controlled by different Rho GTPases. Science 282, 1717-1721. doi: $10.1126 /$ science.282.5394.1717

Carter, R. H., and Fearon, D. T. (1992). CD19: lowering the threshold for antigen receptor stimulation of B lymphocytes. Science 256, 105-107. doi: $10.1126 /$ science. 1373518

Changelian, P. S., and Fearon, D. T. (1986). Tissue-specific phosphorylation of complement receptors CR1 and CR2. J. Exp. Med. 163, 101-115. doi: 10.1084/jem.163.1.101

Chao, T. H., Ember, J. A., Wang, M., Bayon, Y., Hugli, T. E., and Ye, R. D. (1999). Role of the second extracellular loop of human C3a receptor in agonist binding and receptor function. J. Biol. Chem. 274, 9721-9728. doi: 10.1074/jbc.274.14.9721

Chatila, T. A., Geha, R. S., and Arnaout, M. A. (1989). Constitutive and stimulusinduced phosphorylation of CD11/CD18 leukocyte adhesion molecules. J. Cell Biol. 109(6 Pt 2), 3435-3444. doi: 10.1083/jcb.109.6.3435

Chen, J., Crispín, J. C., Dalle Lucca, J., and Tsokos, G. C. (2011). A novel inhibitor of the alternative pathway of complement attenuates intestinal ischemia/reperfusion-induced injury. J. Surg. Res. 167:e131-e136. doi: 10.1016/j.jss.2009.05.041

Chen, W., Lou, J., and Zhu, C. (2010b). Forcing switch from short- to intermediateand long-lived states of the alphaA domain generates LFA-1/ICAM-1 catch bonds. J. Biol. Chem. 285, 35967-35978. doi: 10.1074/jbc.M110.155770

Chen, X., Xie, C., Nishida, N., Li, Z., Walz, T., and Springer, T. A. (2010a). Requirement of open headpiece conformation for activation of leukocyte integrin alphaXbeta2. Proc. Natl. Acad. Sci. U.S.A. 107, 14727-14732. doi: $10.1073 /$ pnas. 1008663107

Chenoweth, D. E., Goodman, M. G., and Weigle, W. O. (1982). Demonstration of a specific receptor for human $\mathrm{C} 5 \mathrm{a}$ anaphylatoxin on murine macrophages. J. Exp. Med. 156, 68-78. doi: 10.1084/jem.156.1.68

Chenoweth, D. E., and Hugli, T. E. (1978). Demonstration of specific C5a receptor on intact human polymorphonuclear leukocytes. Proc. Natl. Acad. Sci. U.S.A. 75, 3943-3947. doi: 10.1073/pnas.75.8.3943

Chtanova, T., Schaeffer, M., Han, S. J., van Dooren, G. G., Nollmann, M., Herzmark, P., et al. (2008). Dynamics of neutrophil migration in lymph nodes during infection. Immunity 29, 487-496. doi: 10.1016/j.immuni.2008.07.012

Cooper, N. R. (1973). Formation and function of a complex of the C3 proactivator with a protein from cobra venom. J. Exp. Med. 137, 451-460. doi: $10.1084 /$ jem.137.2.451
Cooper, N. R. (1985). The classical complement pathway: activation and regulation of the first complement component. Adv. Immunol. 37, 151-216. doi: 10.1016/S0065-2776(08)60340-5

Corbi, A. L., Kishimoto, T. K., Miller, L. J., and Springer, T. A. (1988). The human leukocyte adhesion glycoprotein Mac-1 (complement receptor type 3, CD11b) alpha subunit. Cloning, primary structure, and relation to the integrins, von Willebrand factor and factor B. J. Biol. Chem. 263, 12403-12411. doi: 10.1016/S0021-9258(18)37770-6

Cornacoff, J. B., Hebert, L. A., Smead, W. L., VanAman, M. E., Birmingham, D. J., and Waxman, F. J. (1983). Primate erythrocyte-immune complex-clearing mechanism. J. Clin. Invest. 71, 236-247. doi: 10.1172/JCI110764

Crass, T., Raffetseder, U., Martin, U., Grove, M., Klos, A., Köhl, J., et al. (1996). Expression cloning of the human C3a anaphylatoxin receptor (C3aR) from differentiated U-937 cells. Eur. J. Immunol. 26, 1944-1950. doi: 10.1002/eji.1830260840

Crider, A., Feng, T., Pandya, C. D., Davis, T., Nair, A., Ahmed, A. O., et al. (2018). Complement component 3a receptor deficiency attenuates chronic stress-induced monocyte infiltration and depressive-like behavior. Brain Behav. Immun. 70, 246-256. doi: 10.1016/j.bbi.2018.03.004

Croker, D. E., Halai, R., Fairlie, D. P., and Cooper, M. A. (2013). C5a, but not C5a-des Arg, induces upregulation of heteromer formation between complement C5a receptors C5aR and C5L2. Immunol Cell Biol. 91, 625-633. doi: $10.1038 /$ icb. 2013.48

Croker, D. E., Halai, R., Kaeslin, G., Wende, E., Fehlhaber, B., Klos, A., et al. (2014). C5a2 can modulate ERK1/2 signaling in macrophages via heteromer formation with $\mathrm{C} 5 \mathrm{al}$ and $\beta$-arrestin recruitment. Immunol Cell Biol. 92, 631-639. doi: 10.1038/icb.2014.32

Daffern, P. J., Pfeifer, P. H., Ember, J. A., and Hugli, T. E. (1995). C3a is a chemotaxin for human eosinophils but not for neutrophils. I. C3a stimulation of neutrophils is secondary to eosinophil activation. J. Exp. Med. 181, 2119-2127. doi: 10.1084/jem.181.6.2119

Danielsson, C., Pascual, M., French, L., Steiger, G., and Schifferli, J. A. (1994). Soluble complement receptor type 1 (CD35) is released from leukocytes by surface cleavage. Eur. J. Immunol. 24, 2725-2731. doi: 10.1002/eji.1830241123

Daveau, M., Benard, M., Scotte, M., Schouft, M. T., Hiron, M., Francois, A., et al. (2004). Expression of a functional C5a receptor in regenerating hepatocytes and its involvement in a proliferative signaling pathway in rat. J. Immunol. 173, 3418-3424. doi: 10.4049/jimmunol.173.5.3418

Davies, K. A., Peters, A. M., Beynon, H. L., and Walport, M. J. (1992). Immune complex processing in patients with systemic lupus erythematosus. In vivo imaging and clearance studies. J. Clin. Invest. 90, 2075-2083. doi: 10.1172/JCI116090

Davies, K. A., Schifferli, J. A., and Walport, M. J. (1994). Complement deficiency and immune complex disease. Immunopathol. 15, 397-416. doi: 10.1007/BF01837367

Davoust, N., Jones, J., Stahel, P. F., Ames, R. S., and Barnum, S. R. (1999). Receptor for the C3a anaphylatoxin is expressed by neurons and glial cells. Glia 26, 201-211. doi: 10.1002/(SICI)1098-1136(199905)26:3<201::AID-GLIA2>3. $0 . \mathrm{CO} ; 2-\mathrm{M}$

del Rio, A., Perez-Jimenez, R., Liu, R., Roca-Cusachs, P., Fernandez, J. M., and Sheetz, M. P. (2009). Stretching single talin rod molecules activates vinculin binding. Science 323, 638-641. doi: 10.1126/science.1162912

DeMartino, J. A., Van Riper, G., Siciliano, S. J., Molineaux, C. J., Konteatis, Z. D., Rosen, H., et al. (1994). The amino terminus of the human C5a receptor is required for high affinity $\mathrm{C} 5 \mathrm{a}$ binding and for receptor activation by $\mathrm{C} 5 \mathrm{a}$ but not C5a analogs. J. Biol. Chem. 269, 14446-14450.

Densen, P., and Ram, S. (2015). "Chapter 9 - complement and deficiencies," in Mandell, Douglas, and Bennett's Principles and Practice of Infectious Diseases, eds J. E. Bennett, R. Dolin, M. J. Blaser (Amsterdam: Elsevier), 93-115. doi: 10.1016/B978-1-4557-4801-3.00009-6

Detmers, P. A., Wright, S. D., Olsen, E., Kimball, B., and Cohn, Z. A. (1987) Aggregation of complement receptors on human neutrophils in the absence of ligand. J. Cell Biol. 105, 1137-1145. doi: 10.1083/jcb.105.3.1137

Diamond, M. S., Garcia-Aguilar, J., Bickford, J. K., Corbi, A. L., and Springer, T. A. (1993). The I domain is a major recognition site on the leukocyte integrin Mac1 (CD11b/CD18) for four distinct adhesion ligands. J. Cell Biol. 120, 1031-1043. doi: $10.1083 /$ jcb.120.4.1031 
Diamond, M. S., Staunton, D. E., Marlin, S. D., and Springer, T. A. (1991). Binding of the integrin Mac-1 (CD11b/CD18) to the third immunoglobulinlike domain of ICAM-1 (CD54) and its regulation by glycosylation. Cell 65, 961-971. doi: 10.1016/0092-8674(91)90548-D

Ding, Z. M., Babensee, J. E., Simon, S. I., Lu, H., Perrard, J. L., Bullard, D. C., et al. (1999). Relative contribution of LFA-1 and Mac-1 to neutrophil adhesion and migration. J. Immunol. 163, 5029-5038.

Dishaw, L. J., Smith, S. L., and Bigger, C. H. (2005). Characterization of a C3like cDNA in a coral: phylogenetic implications. Immunogenetics 57, 535-548. doi: 10.1007/s00251-005-0005-1

Dodds, A. W., and Matsushita, M. (2007). The phylogeny of the complement system and the origins of the classical pathway. Immunobiology 212, 233-243. doi: 10.1016/j.imbio.2006.11.009

Donius, L. R., Handy, J. M., Weis, J. J., and Weis, J. H. (2013). Optimal germinal center $\mathrm{B}$ cell activation and $\mathrm{T}$-dependent antibody responses require expression of the mouse complement receptor Cr1. J. Immunol. 191, 434-447. doi: 10.4049/jimmunol.1203176

Drouin, S. M., Kildsgaard, J., Haviland, J., Zabner, J., Jia, H. P., McCray, P. B., et al. (2001). Expression of the complement anaphylatoxin C3a and C5a receptors on bronchial epithelial and smooth muscle cells in models of sepsis and asthma. J. Immunol. 166, 2025-2032. doi: 10.4049/jimmunol.166.3.2025

Dustin, M. L., and Springer, T. A. (1988). Lymphocyte function-associated antigen1 (LFA-1) interaction with intercellular adhesion molecule-1 (ICAM-1) is one of at least three mechanisms for lymphocyte adhesion to cultured endothelial cells. J. Cell Biol. 107, 321-331. doi: 10.1083/jcb.107.1.321

Ehlenberger, A. G., and Nussenzweig, V. (1977). The role of membrane receptors for $\mathrm{C} 3 \mathrm{~b}$ and $\mathrm{C} 3 \mathrm{~d}$ in phagocytosis. J. Exp. Med. 145, 357-371. doi: $10.1084 /$ jem.145.2.357

Elices, M. J., Osborn, L., Takada, Y., Crouse, C., Luhowskyj, S., Hemler, M. E., et al. (1990). VCAM-1 on activated endothelium interacts with the leukocyte integrin VLA-4 at a site distinct from the VLA-4/fibronectin binding site. Cell 60, 577-584. doi: 10.1016/0092-8674(90)90661-W

Elsner, J., Oppermann, M., Czech, W., and Kapp, A. (1994). C3a activates the respiratory burst in human polymorphonuclear neutrophilic leukocytes via pertussis toxin-sensitive G-proteins. Blood 83, 3324-3331. doi: 10.1182/blood.V83.11.3324.3324

Erdei, A., Lukacsi, S., Macsik-Valent, B., Nagy-Balo, Z., Kurucz, I., and Bajtay, Z. (2019). Non-identical twins: different faces of CR3 and CR4 in myeloid and lymphoid cells of mice and men. Semin Cell Dev. Biol. 85, 110-121. doi: 10.1016/j.semcdb.2017.11.025

Fagerholm, S. C., Varis, M., Stefanidakis, M., Hilden, T. J., and Gahmberg, C. G. (2006). alpha-Chain phosphorylation of the human leukocyte CD11b/CD18 (Mac-1) integrin is pivotal for integrin activation to bind ICAMs and leukocyte extravasation. Blood 108, 3379-3386. doi: 10.1182/blood-2006-03-013557

Fällman, M., Andersson, R., and Andersson, T. (1993). Signaling properties of CR3 (CD11b/CD18) and CR1 (CD35) in relation to phagocytosis of complementopsonized particles. J. Immunol. 151, 330-338.

Fang, Y., Xu, C., Fu, Y. X., Holers, V. M., and Molina, H. (1998). Expression of complement receptors 1 and 2 on follicular dendritic cells is necessary for the generation of a strong antigen-specific IgG response. J. Immunol. 160, 5273-5279.

Faridi, M. H., Khan, S. Q., Zhao, W., Lee, H. W., Altintas, M. M., Zhang, K., et al. (2017). CD11b activation suppresses TLR-dependent inflammation and autoimmunity in systemic lupus erythematosus. J. Clin. Invest. 127, 1271-1283. doi: $10.1172 /$ JCI88442

Farzan, M., Schnitzler, C. E., Vasilieva, N., Leung, D., Kuhn, J., Gerard, C., et al. (2001). Sulfated tyrosines contribute to the formation of the C5a docking site of the human C5a anaphylatoxin receptor. J. Exp. Med. 193, 1059-1066. doi: 10.1084/jem.193.9.1059

Fearon, D. T. (1980). Identification of the membrane glycoprotein that is the $\mathrm{C} 3 \mathrm{~b}$ receptor of the human erythrocyte, polymorphonuclear leukocyte, B lymphocyte, and monocyte. J. Exp. Med. 152, 20-30. doi: 10.1084/jem.152.1.20

Fearon, D. T., Kaneko, I., and Thomson, G. G. (1981). Membrane distribution and adsorptive endocytosis by $\mathrm{C} 3 \mathrm{~b}$ receptors on human polymorphonuclear leukocytes. J. Exp. Med. 153, 1615-1628. doi: 10.1084/jem.153.6.1615

Fernandez, H. N., Henson, P. M., Otani, A., and Hugli, T. E. (1978). Chemotactic response to human $\mathrm{C} 3 \mathrm{a}$ and $\mathrm{C} 5 \mathrm{a}$ anaphylatoxins. I. Evaluation of $\mathrm{C} 3 \mathrm{a}$ and
C5a leukotaxis in vitro and under stimulated in vivo conditions. J. Immunol. $120,109-115$.

Fernandez, H. N., and Hugli, T. E. (1978). Primary structural analysis of the polypeptide portion of human $\mathrm{C} 5 \mathrm{a}$ anaphylatoxin. Polypeptide sequence determination and assignment of the oligosaccharide attachment site in C5a. J. Biol. Chem. 253, 6955-6964. doi: 10.1016/S0021-9258(17)38013-4

Filippi, M. D. (2019). Neutrophil transendothelial migration: updates and new perspectives. Blood 133, 2149-2158. doi: 10.1182/blood-2018-12-844605

Fingeroth, J. D., Weis, J. J., Tedder, T. F., Strominger, J. L., Biro, P. A., and Fearon, D. T. (1984). Epstein-Barr virus receptor of human B lymphocytes is the C3d receptor CR2. Proc. Natl. Acad. Sci. U.S.A. 81, 4510-4514. doi: $10.1073 /$ pnas.81.14.4510

Fischer, W. H., and Hugli, T. E. (1997). Regulation of B cell functions by C3a and C3a(desArg): suppression of TNF-alpha, IL-6, and the polyclonal immune response. J. Immunol. 159, 4279-4286.

Flannagan, R. S., Jaumouille, V., and Grinstein, S. (2012). The cell biology of phagocytosis. Annu. Rev. Pathol. 7, 61-98. doi: 10.1146/annurev-pathol-011811-132445

Flick, M. J., Du, X., Witte, D. P., Jirouskova, M., Soloviev, D. A., Busuttil, S. J., et al. (2004). Leukocyte engagement of fibrin(ogen) via the integrin receptor alphaMbeta2/Mac-1 is critical for host inflammatory response in vivo. J. Clin. Invest. 113, 1596-1606. doi: 10.1172/JCI20741

Freeman, S. A., and Grinstein, S. (2014). Phagocytosis: receptors, signal integration, and the cytoskeleton. Immunol Rev. 262, 193-215. doi: $10.1111 /$ imr.12212

Füreder, W., Agis, H., Willheim, M., Bankl, H. C., Maier, U., Kishi, K., et al. (1995). Differential expression of complement receptors on human basophils and mast cells. Evidence for mast cell heterogeneity and CD88/C5aR expression on skin mast cells. J. Immunol. 155, 3152-3160.

Futosi, K., Fodor, S., and Mócsai, A. (2013). Reprint of Neutrophil cell surface receptors and their intracellular signal transduction pathways. Int. Immunopharmacol. 17, 1185-1197. doi: 10.1016/j.intimp.2013. 11.010

Gaipl, U. S., Kuenkele, S., Voll, R. E., Beyer, T. D., Kolowos, W., Heyder, P., et al. (2001). Complement binding is an early feature of necrotic and a rather late event during apoptotic cell death. Cell Death Differ. 8, 327-334. doi: 10.1038/sj.cdd.4400826

Gasque, P., Singhrao, S. K., Neal, J. W., Wang, P., Sayah, S., Fontaine, M., et al. (1998). The receptor for complement anaphylatoxin C3a is expressed by myeloid cells and nonmyeloid cells in inflamed human central nervous system: analysis in multiple sclerosis and bacterial meningitis. J. Immunol. 160, 3543-3554.

Gerard, N. P., Bao, L., Xiao-Ping, H., Eddy, R. L., Shows, T. B., and Gerard, C. (1993). Human chemotaxis receptor genes cluster at 19q13.3-13.4. Characterization of the human C5a receptor gene. Biochemistry 32, 1243-1250. doi: 10.1021/bi00056a007

Gerard, N. P., and Gerard, C. (1991). The chemotactic receptor for human C5a anaphylatoxin. Nature 349, 614-617. doi: 10.1038/349614a0

Gerhardt, T., and Ley, K. (2015). Monocyte trafficking across the vessel wall. Cardiovasc Res. 107, 321-330. doi: 10.1093/cvr/cvv147

Ghiran, I., Barbashov, S. F., Klickstein, L. B., Tas, S. W., Jensenius, J. C., and Nicholson-Weller, A. (2000). Complement receptor $1 /$ CD35 is a receptor for mannan-binding lectin. J. Exp. Med. 192, 1797-1808. doi: 10.1084/jem.192.12.1797

Giagulli, C., Ottoboni, L., Caveggion, E., Rossi, B., Lowell, C., Constantin, G., et al. (2006). The Src family kinases Hck and Fgr are dispensable for insideout, chemoattractant-induced signaling regulating beta 2 integrin affinity and valency in neutrophils, but are required for beta 2 integrin-mediated outside-in signaling involved in sustained adhesion. J. Immunol. 177, 604-611. doi: 10.4049/jimmunol.177.1.604

Gigli, I., and Nelson, R. A. (1968). Complement dependent immune phagocytosis. I. Requirements for C'1, C'4, C'2, C’3. Exp. Cell Res. 51, 45-67. doi: 10.1016/0014-4827(68)90158-4

Gorgani, N. N., He, J. Q., Katschke, K. J., Helmy, K. Y., Xi, H., Steffek, M., et al. (2008). Complement receptor of the Ig superfamily enhances complementmediated phagocytosis in a subpopulation of tissue resident macrophages. $J$. Immunol. 181, 7902-7908. doi: 10.4049/jimmunol.181.11.7902 
Gregory, S. H., Cousens, L. P., van Rooijen, N., Döpp, E. A., Carlos, T. M., and Wing, E. J. (2002). Complementary adhesion molecules promote neutrophilKupffer cell interaction and the elimination of bacteria taken up by the liver. J. Immunol. 168, 308-315. doi: 10.4049/jimmunol.168.1.308

Griffin, F. M., Griffin, J. A., Leider, J. E., and Silverstein, S. C. (1975). Studies on the mechanism of phagocytosis. I. Requirements for circumferential attachment of particle-bound ligands to specific receptors on the macrophage plasma membrane. J. Exp. Med. 142, 1263-1282. doi: 10.1084/jem.142.5.1263

Guglietta, S., Chiavelli, A., Zagato, E., Krieg, C., Gandini, S., Ravenda, P. S., et al. (2016). Coagulation induced by C3aR-dependent NETosis drives protumorigenic neutrophils during small intestinal tumorigenesis. Nat. Commun. 7:11037. doi: 10.1038/ncomms11037

Gullstrand, B., Martensson, U., Sturfelt, G., Bengtsson, A. A., and Truedsson, L. (2009). Complement classical pathway components are all important in clearance of apoptotic and secondary necrotic cells. Clin. Exp. Immunol. 156, 303-311. doi: 10.1111/j.1365-2249.2009.03896.x

Hajishengallis, G., Reis, E. S., Mastellos, D. C., Ricklin, D., and Lambris, J. D. (2017). Novel mechanisms and functions of complement. Nat. Immunol. 18, 1288-1298. doi: 10.1038/ni.3858

Halai, K., Whiteford, J., Ma, B., Nourshargh, S., and Woodfin, A. (2014). ICAM2 facilitates luminal interactions between neutrophils and endothelial cells in vivo. J. Cell Sci. 127(Pt 3), 620-629. doi: 10.1242/jcs.137463

Hall, A. B., Gakidis, M. A., Glogauer, M., Wilsbacher, J. L., Gao, S., Swat, W., et al. (2006). Requirements for Vav guanine nucleotide exchange factors and Rho GTPases in FcgammaR- and complement-mediated phagocytosis. Immunity 24, 305-316. doi: 10.1016/j.immuni.2006.02.005

Hannan, J., Young, K., Szakonyi, G., Overduin, M. J., Perkins, S. J., Chen, X., et al. (2002). Structure of complement receptor (CR) 2 and CR2-C3d complexes. Biochem. Soc. Trans. 30(Pt 6), 983-989. doi: 10.1042/bst0300983

Hannan, J. P., Young, K. A., Guthridge, J. M., Asokan, R., Szakonyi, G., Chen, X. S., et al. (2005). Mutational analysis of the complement receptor type 2 (CR2/CD21)-C3d interaction reveals a putative charged SCR1 binding site for C3d. J. Mol. Biol. 346, 845-858. doi: 10.1016/j.jmb.2004.12.007

Hartmann, K., Henz, B. M., Krüger-Krasagakes, S., Köhl, J., Burger, R., Guhl, S., et al. (1997). C3a and C5a stimulate chemotaxis of human mast cells. Blood 89, 2863-2870. doi: 10.1182/blood.V89.8.2863

Haviland, D. L., McCoy, R. L., Whitehead, W. T., Akama, H., Molmenti, E. P., Brown, A., et al. (1995). Cellular expression of the C5a anaphylatoxin receptor (C5aR): demonstration of C5aR on nonmyeloid cells of the liver and lung. J. Immunol. 154, 1861-1869.

Helmy, K. Y., Katschke, K. J., Gorgani, N. N., Kljavin, N. M., Elliott, J. M., Diehl, L., et al. (2006). CRIg: a macrophage complement receptor required for phagocytosis of circulating pathogens. Cell 124, 915-927. doi: $10.1016 /$ j.cell.2005.12.039

Ho, M. K., and Springer, T. A. (1982). Mac-1 antigen: quantitative expression in macrophage populations and tissues, and immunofluorescent localization in spleen. J. Immunol. 128, 2281-2286.

Hogg, N., Stewart, M. P., Scarth, S. L., Newton, R., Shaw, J. M., Law, S. K., et al. (1999). A novel leukocyte adhesion deficiency caused by expressed but nonfunctional beta2 integrins Mac-1 and LFA-1. J. Clin. Invest. 103, 97-106. doi: $10.1172 / \mathrm{JCI} 3312$

Holers, V. M. (2014). Complement and its receptors: new insights into human disease. Annu. Rev. Immunol. 32, 433-459. doi: 10.1146/annurev-immunol-032713-120154

Hornum, L., Hansen, A. J., Tornehave, D., Fjording, M. S., Colmenero, P., Wätjen, I. F., et al. (2017). C5a and C5aR are elevated in joints of rheumatoid and psoriatic arthritis patients, and C5aR blockade attenuates leukocyte migration to synovial fluid. PLoS ONE 12:e189017. doi: 10.1371/journal.pone.0 189017

Horwitz, M. A., and Silverstein, S. C. (1980). Influence of the Escherichia coli capsule on complement fixation and on phagocytosis and killing by human phagocytes. J. Clin. Invest. 65, 82-94. doi: 10.1172/JCI109663

Hu, C., Li, L., Ding, P., Ge, X., Zheng, L., Wang, X., et al. (2019). Complement Inhibitor CRIg/FH Ameliorates Renal Ischemia Reperfusion Injury via Activation of PI3K/AKT Signaling. J. Immunol. 201, 3717-3730. doi: 10.4049/jimmunol.1800987

Huang, M. T., Larbi, K. Y., Scheiermann, C., Woodfin, A., Gerwin, N., Haskard, D. O., et al. (2006). ICAM-2 mediates neutrophil transmigration in vivo: evidence for stimulus specificity and a role in PECAM-1-independent transmigration. Blood 107, 4721-4727. doi: 10.1182/blood-2005-11-4683

Huber, R., Scholze, H., Pâques, E. P., and Deisenhofer, J. (1980). Crystal structure analysis and molecular model of human C3a anaphylatoxin. Hoppe Seylers $Z$ Physiol Chem 361, 1389-1399. doi: 10.1515/bchm2.1980.361.2.1389

Hugli, T. E. (1975). Human anaphylatoxin (C3a) from the third component of complement. Primary structure. J. Biol. Chem. 250, 8293-8301. doi: 10.1016/S0021-9258(19)40758-8

Huo, Y., Hafezi-Moghadam, A., and Ley, K. (2000). Role of vascular cell adhesion molecule-1 and fibronectin connecting segment-1 in monocyte rolling and adhesion on early atherosclerotic lesions. Circ. Res. 87, 153-159. doi: 10.1161/01.RES.87.2.153

Hyams, C., Camberlein, E., Cohen, J. M., Bax, K., and Brown, J. S. (2010). The Streptococcus pneumoniae capsule inhibits complement activity and neutrophil phagocytosis by multiple mechanisms. Infect. Immun. 78, 704-715. doi: 10.1128/IAI.00881-09

Hyduk, S. J., Chan, J. R., Duffy, S. T., Chen, M., Peterson, M. D., Waddell, T. K., et al. (2007). Phospholipase C, calcium, and calmodulin are critical for alpha4beta1 integrin affinity up-regulation and monocyte arrest triggered by chemoattractants. Blood 109, 176-184. doi: 10.1182/blood-2006-01-029199

Hynes, R. O. (1992). Integrins: versatility, modulation, and signaling in cell adhesion. Cell 69, 11-25. doi: 10.1016/0092-8674(92)90115-S

Iida, K., and Nussenzweig, V. (1981). Complement receptor is an inhibitor of the complement cascade. J. Exp. Med. 153, 1138-1150. doi: 10.1084/jem.153.5.1138

Imrie, H. J., and Jones, D. R. (1997). Complement coating of erythrocytes is reduced following their interaction with neutrophils in vitro without loss of complement receptor 1 (CR1). Clin. Exp. Immunol. 109, 217-222. doi: 10.1046/j.1365-2249.1997.4151312.x

Jacobson, A. C., and Weis, J. H. (2008). Comparative functional evolution of human and mouse CR1 and CR2. J. Immunol. 181, 2953-2959. doi: 10.4049/jimmunol.181.5.2953

Jaumouille, V., Cartagena-Rivera, A. X., and Waterman, C. M. (2019). Coupling of beta2 integrins to actin by a mechanosensitive molecular clutch drives complement receptor-mediated phagocytosis. Nat. Cell Biol. 21, 1357-1369. doi: 10.1038/s41556-019-0414-2

Johnson, A. R., Hugli, T. E., and Müller-Eberhard, H. J. (1975). Release of histamine from rat mast cells by the complement peptides C3a and C5a. Immunology 28, 1067-1080.

Jongstra-Bilen, J., Harrison, R., and Grinstein, S. (2003). Fcgamma-receptors induce Mac-1 (CD11b/CD18) mobilization and accumulation in the phagocytic cup for optimal phagocytosis. J. Biol. Chem. 278, 45720-45729. doi: 10.1074/jbc.M303704200

Jung, K., Kang, M., Park, C., Hyun Choi, Y., Jeon, Y., Park, S. H., et al. (2012). Protective role of V-set and immunoglobulin domain-containing 4 expressed on kupffer cells during immune-mediated liver injury by inducing tolerance of liver T- and natural killer T-cells. Hepatology 56, 1838-1848. doi: $10.1002 /$ hep. 25906

Kamitaki, N., Sekar, A., Handsaker, R. E., de Rivera, H., Tooley, K., Morris, D. L., et al. (2020). Complement genes contribute sex-biased vulnerability in diverse disorders. Nature 582, 577-581. doi: 10.1038/s41586-020-2277-x

Kaplan, G. (1977). Differences in the mode of phagocytosis with Fc and C3 receptors in macrophages. Scand J. Immunol. 6, 797-807. doi: 10.1111/j.1365-3083.1977.tb02153.x

Katschke, K. J., Helmy, K. Y., Steffek, M., Xi, H., Yin, J., Lee, W. P., et al. (2007). A novel inhibitor of the alternative pathway of complement reverses inflammation and bone destruction in experimental arthritis. J. Exp. Med. 204, 1319-1325. doi: 10.1084/jem.20070432

Keizer, G. D., Te Velde, A. A., Schwarting, R., Figdor, C. G., and De Vries, J. E. (1987). Role of p150,95 in adhesion, migration, chemotaxis and phagocytosis of human monocytes. Eur. J. Immunol. 17, 1317-1322. doi: 10.1002/eji.1830170915

Kienle, K., and Lämmermann, T. (2016). Neutrophil swarming: an essential process of the neutrophil tissue response. Immunol. Rev. 273, 76-93. doi: 10.1111/imr.12458

Kim, Y. U., Kinoshita, T., Molina, H., Hourcade, D., Seya, T., Wagner, L. M., et al. (1995). Mouse complement regulatory protein Crry/p65 uses the specific mechanisms of both human decay-accelerating factor and membrane cofactor protein. J. Exp. Med. 181, 151-159. doi: 10.1084/jem.181.1.151 
Kinoshita, T., Lavoie, S., and Nussenzweig, V. (1985). Regulatory proteins for the activated third and fourth components of complement (C3b and C4b) in mice. II. Identification and properties of complement receptor type 1 (CR1). J. Immunol. 134, 2564-2570.

Klapproth, S., Sperandio, M., Pinheiro, E. M., Prunster, M., Soehnlein, O., Gertler, F. B., et al. (2015). Loss of the Rap1 effector RIAM results in leukocyte adhesion deficiency due to impaired beta2 integrin function in mice. Blood 126 , 2704-2712. doi: 10.1182/blood-2015-05-647453

Klaus, G. G., and Humphrey, J. H. (1977). The generation of memory cells. I. The role of C3 in the generation of B memory cells. Immunology 33, 31-40.

Klickstein, L. B., Bartow, T. J., Miletic, V., Rabson, L. D., Smith, J. A., and Fearon, D. T. (1988). Identification of distinct C3b and C4b recognition sites in the human C3b/C4b receptor (CR1, CD35) by deletion mutagenesis. J. Exp. Med. 168, 1699-1717. doi: 10.1084/jem.168.5.1699

Kouser, L., Madhukaran, S. P., Shastri, A., Saraon, A., Ferluga, J., Al-Mozaini, M., et al. (2015). Emerging and Novel Functions of Complement Protein C1q. Front. Immunol. 6:317. doi: 10.3389/fimmu.2015.00317

Krych, M., Hourcade, D., and Atkinson, J. P. (1991). Sites within the complement $\mathrm{C} 3 \mathrm{~b} / \mathrm{C} 4 \mathrm{~b}$ receptor important for the specificity of ligand binding. Proc. Natl. Acad. Sci. U.S.A. 88, 4353-4357. doi: 10.1073/pnas.88.10.4353

Kürzinger, K., Reynolds, T., Germain, R. N., Davignon, D., Martz, E., and Springer, T. A. (1981). A novel lymphocyte function-associated antigen (LFA-1): cellular distribution, quantitative expression, and structure. J. Immunol. 127, 596-602.

Kuwano, Y., Spelten, O., Zhang, H., Ley, K., and Zarbock, A. (2010). Rolling on Eor P-selectin induces the extended but not high-affinity conformation of LFA-1 in neutrophils. Blood 116, 617-624. doi: 10.1182/blood-2010-01-266122

Lämmermann, T. (2016). In the eye of the neutrophil swarm-navigation signals that bring neutrophils together in inflamed and infected tissues. J. Leukoc. Biol. 100, 55-63. doi: 10.1189/jlb.1MR0915-403

Lämmermann, T., Afonso, P. V., Angermann, B. R., Wang, J. M., Kastenmüller, W., Parent, C. A., et al. (2013). Neutrophil swarms require LTB4 and integrins at sites of cell death in vivo. Nature 498, 371-375. doi: 10.1038/nature12175

Lämmermann, T., Bader, B. L., Monkley, S. J., Worbs, T., Wedlich-Söldner, R., Hirsch, K., et al. (2008). Rapid leukocyte migration by integrin-independent flowing and squeezing. Nature 453, 51-55. doi: 10.1038/nature06887

Langnaese, K., Colleaux, L., Kloos, D. U., Fontes, M., and Wieacker, P. (2000). Cloning of Z39Ig, a novel gene with immunoglobulin-like domains located on human chromosome X. Biochim Biophys Acta 1492, 522-525. doi: 10.1016/S0167-4781(00)00131-7

Le Cabec, V., Carreno, S., Moisand, A., Bordier, C., and Maridonneau-Parini, I. (2002). Complement receptor $3(\mathrm{CD} 11 \mathrm{~b} / \mathrm{CD} 18)$ mediates type I and type II phagocytosis during nonopsonic and opsonic phagocytosis, respectively. J. Immunol. 169, 2003-2009. doi: 10.4049/jimmunol.169.4.2003

Lee, J. O., Rieu, P., Arnaout, M. A., and Liddington, R. (1995). Crystal structure of the A domain from the alpha subunit of integrin CR3 (CD11b/CD18). Cell 80, 631-638. doi: 10.1016/0092-8674(95)90517-0

Lefort, C. T., and Ley, K. (2012). Neutrophil arrest by LFA-1 activation. Front. Immunol. 3:157. doi: 10.3389/fimmu.2012.00157

Lewis, M. J., and Botto, M. (2006). Complement deficiencies in humans and animals: links to autoimmunity. Autoimmunity 39, 367-378. doi: 10.1080/08916930600739233

Li, X. X., Lee, J. D., Kemper, C., and Woodruff, T. M. (2019). The complement receptor C5aR2: a powerful modulator of innate and adaptive immunity. J. Immunol. 202, 3339-3348. doi: 10.4049/jimmunol.1900371

Lieberman, L. A., Mizui, M., Nalbandian, A., Bossé R., Crispín, J. C., and Tsokos, G. C. (2015). Complement receptor of the immunoglobulin superfamily reduces murine lupus nephritis and cutaneous disease. Clin. Immunol. 160, 286-291. doi: 10.1016/j.clim.2015.05.006

Liu, G., Fu, Y., Yosri, M., Chen, Y., Sun, P., Xu, J., et al. (2016). CRIg plays an essential role in intravascular clearance of bloodborne parasites by interacting with complement. Proc. Natl. Acad. Sci. U.S.A. 116, 24214-20. doi: 10.1073/pnas.1913443116

Liu, J. R., Han, X., Soriano, S. G., and Yuki, K. (2014). The role of macrophage 1 antigen in polymicrobial sepsis. Shock 42, 532-539. doi: $10.1097 /$ SHK.0000000000000250

Luo, B. H., Carman, C. V., and Springer, T. A. (2007). Structural basis of integrin regulation and signaling. Annu. Rev. Immunol. 25, 619-647. doi: 10.1146/annurev.immunol.25.022106.141618
Mantovani, B. (1975). Different roles of IgG and complement receptors in phagocytosis by polymorphonuclear leukocytes. J. Immunol. 115, 15-17.

Markiewski, M. M., Mastellos, D., Tudoran, R., DeAngelis, R. A., Strey, C. W., Franchini, S., et al. (2004). C3a and C3b activation products of the third component of complement (C3) are critical for normal liver recovery after toxic injury. J. Immunol. 173, 747-754. doi: 10.4049/jimmunol.173.2.747

Marshall, K. M., He, S., Zhong, Z., Atkinson, C., and Tomlinson, S. (2014). Dissecting the complement pathway in hepatic injury and regeneration with a novel protective strategy. J. Exp. Med. 211, 1793-1805. doi: $10.1084 /$ jem.20131902

Martin, U., Bock, D., Arseniev, L., Tornetta, M. A., Ames, R. S., Bautsch, W., et al. (1997). The human C3a receptor is expressed on neutrophils and monocytes, but not on B or T lymphocytes. J. Exp. Med. 186, 199-207. doi: $10.1084 /$ jem.186.2.199

Masaki, T., Matsumoto, M., Nakanishi, I., Yasuda, R., and Seya, T. (1992). Factor Idependent inactivation of human complement $\mathrm{C} 4 \mathrm{~b}$ of the classical pathway by $\mathrm{C} 3 \mathrm{~b} / \mathrm{C} 4 \mathrm{~b}$ receptor (CR1, CD35) and membrane cofactor protein (MCP, CD46). J. Biochem. 111, 573-578. doi: 10.1093/oxfordjournals.jbchem.a123799

Massena, S., Christoffersson, G., Hjertström, E., Zcharia, E., Vlodavsky, I., Ausmees, N., et al. (2010). A chemotactic gradient sequestered on endothelial heparan sulfate induces directional intraluminal crawling of neutrophils. Blood 116, 1924-1931. doi: 10.1182/blood-2010-01-266072

Mastellos, D., Papadimitriou, J. C., Franchini, S., Tsonis, P. A., and Lambris, J. D. (2001). A novel role of complement: mice deficient in the fifth component of complement (C5) exhibit impaired liver regeneration. J. Immunol. 166, 2479-2486. doi: 10.4049/jimmunol.166.4.2479

Mastellos, D. C., Ricklin, D., and Lambris, J. D. (2019). Clinical promise of next-generation complement therapeutics. Nat. Rev. Drug Discov. 18, 707-729. doi: 10.1038/s41573-019-0031-6

Mathew, E. C., Shaw, J. M., Bonilla, F. A., Law, S. K., and Wright, D. A. (2000). A novel point mutation in CD18 causing the expression of dysfunctional CD11/CD18 leucocyte integrins in a patient with leucocyte adhesion deficiency (LAD). Clin. Exp. Immunol. 121, 133-138. doi: 10.1046/j.1365-2249.2000.01277.x

Matthews, K. W., Mueller-Ortiz, S. L., and Wetsel, R. A. (2004). Carboxypeptidase $\mathrm{N}$ : a pleiotropic regulator of inflammation. Mol. Immunol. 40, 785-793. doi: 10.1016/j.molimm.2003.10.002

May, R. C., Caron, E., Hall, A., and Machesky, L. M. (2000). Involvement of the Arp2/3 complex in phagocytosis mediated by FcgammaR or CR3. Nat. Cell Biol. 2, 246-248. doi: $10.1038 / 35008673$

May, R. C., and Machesky, L. M. (2001). Phagocytosis and the actin cytoskeleton. J. Cell Sci. 114(Pt 6), 1061-1077.

McEver, R. P. (2002). Selectins: lectins that initiate cell adhesion under flow. Curr. Opin. Cell Biol. 14, 581-586. doi: 10.1016/S0955-0674(02)00367-8

Medzhitov, R. (2008). Origin and physiological roles of inflammation. Nature 454, 428-435. doi: 10.1038/nature07201

Meerschaert, J., and Furie, M. B. (1995). The adhesion molecules used by monocytes for migration across endothelium include CD11a/CD18, CD11b/CD18, and VLA-4 on monocytes and ICAM-1, VCAM-1, and other ligands on endothelium. J. Immunol. 154, 4099-4112.

Merle, N. S., Church, S. E., Fremeaux-Bacchi, V., and Roumenina, L. T. (2015). Complement System Part I - Molecular Mechanisms of Activation and Regulation. Front. Immunol. 6:262. doi: 10.3389/fimmu.2015.00262

Mery, L., and Boulay, F. (1994). The NH2-terminal region of C5aR but not that of FPR is critical for both protein transport and ligand binding. J. Biol. Chem. 269, 3457-3463. doi: 10.1016/S0021-9258(17)41884-9

Mevorach, D., Mascarenhas, J. O., Gershov, D., and Elkon, K. B. (1998). Complement-dependent clearance of apoptotic cells by human macrophages. J. Exp. Med. 188, 2313-2320. doi: 10.1084/jem.188.12.2313

Michishita, M., Videm, V., and Arnaout, M. A. (1993). A novel divalent cation-binding site in the $\mathrm{A}$ domain of the beta 2 integrin CR3 (CD11b/CD18) is essential for ligand binding. Cell 72, 857-867. doi: 10.1016/0092-8674(93)90575-B

Middleton, J., Neil, S., Wintle, J., Clark-Lewis, I., Moore, H., Lam, C., et al. (1997). Transcytosis and surface presentation of IL-8 by venular endothelial cells. Cell 91, 385-395. doi: 10.1016/S0092-8674(00)80422-5

Miot, S., Marfurt, J., Lach-Trifilieff, E., González-Rubio, C., López-Trascasa, M., Sadallah, S., et al. (2002). The mechanism of loss of CR1 during maturation of 
erythrocytes is different between factor I deficient patients and healthy donors. Blood Cells Mol. Dis. 29, 200-212. doi: 10.1006/bcmd.2002.0559

Miyabe, Y., Miyabe, C., Mani, V., Mempel, T. R., and Luster, A. D. (2019). Atypical complement receptor $\mathrm{C} 5 \mathrm{aR} 2$ transports $\mathrm{C} 5 \mathrm{a}$ to initiate neutrophil adhesion and inflammation. Sci. Immunol. 4:eaav5951. doi: 10.1126/sciimmunol.aav5951

Miyabe, Y., Miyabe, C., Murooka, T. T., Kim, E. Y., Newton, G. A., Kim, N. D., et al. (2017). Complement C5a Receptor is the key initiator of neutrophil adhesion igniting immune complex-induced arthritis. Sci. Immunol. 2:eaj2195. doi: 10.1126/sciimmunol.aj2195

Molina, H., Kinoshita, T., Webster, C. B., and Holers, V. M. (1994). Analysis of $\mathrm{C} 3 \mathrm{~b} / \mathrm{C} 3 \mathrm{~d}$ binding sites and factor I cofactor regions within mouse complement receptors 1 and 2. J. Immunol. 153, 789-795.

Moon, K. E., Gorski, J. P., and Hugli, T. E. (1981). Complete primary structure of human C4a anaphylatoxin. J. Biol. Chem. 256, 8685-8692. doi: 10.1016/S0021-9258(19)68898-8

Morgan, E. L., Ember, J. A., Sanderson, S. D., Scholz, W., Buchner, R., Ye, R. D., et al. (1993). Anti-C5a receptor antibodies. Characterization of neutralizing antibodies specific for a peptide, $\mathrm{C} 5 \mathrm{aR}$, derived from the predicted aminoterminal sequence of the human C5a receptor. J. Immunol. 151, 377-388.

Moser, M., Nieswandt, B., Ussar, S., Pozgajova, M., and Fässler, R. (2008). Kindlin3 is essential for integrin activation and platelet aggregation. Nat. Med. 14, 325-330. doi: 10.1038/nm1722

Muller, W. A. (2013). Getting leukocytes to the site of inflammation. Vet. Pathol. 50, 7-22. doi: 10.1177/0300985812469883

Müller-Eberhard, H. J. (1986). The membrane attack complex of complement. Annu. Rev. Immunol. 4, 503-528. doi: 10.1146/annurev.iy.04.040186.002443

Munawara, U., Perveen, K., Small, A. G., Putty, T., Quach, A., Gorgani, N. N., et al. (2019). Human dendritic cells express the complement receptor immunoglobulin which regulates T cell responses. Front. Immunol. 10:2892. doi: $10.3389 /$ fimmu. 2019.02892

Nakao, M., and Somamoto, T. (2016). "Chapter 6 - the evolution of complement system functions and pathways in vertebrates, in The Evolution of the Immune System, ed M. Davide (Academic Press), 151-171. doi: 10.1016/B978-0-12-801975-7.00006-2

Nataf, S., Davoust, N., Ames, R. S., and Barnum, S. R. (1999). Human T cells express the C5a receptor and are chemoattracted to C5a. J. Immunol. 162, 4018-4023.

Nath, S. K., Han, S., Kim-Howard, X., Kelly, J. A., Viswanathan, P., Gilkeson, G. S., et al. (2008). A nonsynonymous functional variant in integrin-alpha(M) (encoded by ITGAM) is associated with systemic lupus erythematosus. Nat. Genet. 40, 152-154. doi: 10.1038/ng.71

Nelson, R. A. (1953). The immune-adherence phenomenon; an immunologically specific reaction between microorganisms and erythrocytes leading to enhanced phagocytosis. Science 118, 733-737. doi: 10.1126/science.118.3077.733

Nermut, M. V., Green, N. M., Eason, P., Yamada, S. S., and Yamada, K. M. (1988). Electron microscopy and structural model of human fibronectin receptor. $E M B O ~ J .7,4093-4099$. doi: 10.1002/j.1460-2075.1988.t b03303.x

Neupane, A. S., Willson, M., Chojnacki, A. K., Vargas, E. S. C. F., Morehouse, C., Carestia, A., et al. (2020). Patrolling alveolar macrophages conceal bacteria from the immune system to maintain homeostasis. Cell 183, 110-125.e11. doi: 10.1016/j.cell.2020.08.020

Newman, S. L., Becker, S., and Halme, J. (1985). Phagocytosis by receptors for C3b (CR1), iC3b (CR3), and IgG (Fc) on human peritoneal macrophages. J. Leukoc. Biol. 38, 267-278. doi: 10.1002/jlb.38.2.267

Newman, S. L., Devery-Pocius, J. E., Ross, G. D., and Henson, P. M. (1984). Phagocytosis by human monocyte-derived macrophages. Independent function of receptors for C3b (CR1) and iC3b (CR3). Complement 1, 213-227. doi: $10.1159 / 000467840$

Nishida, N., Xie, C., Shimaoka, M., Cheng, Y., Walz, T., and Springer, T. A. (2006). Activation of leukocyte beta2 integrins by conversion from bent to extended conformations. Immunity 25, 583-594. doi: 10.1016/j.immuni.2006.07.016

Nonaka, M. (2014). Evolution of the complement system. Subcell Biochem. 80, 31-43. doi: 10.1007/978-94-017-8881-6_3

Nordenfelt, P., and Tapper, H. (2011). Phagosome dynamics during phagocytosis by neutrophils. J. Leukoc. Biol. 90, 271-284. doi: 10.1189/jlb.0810457

Norgauer, J., Dobos, G., Kownatzki, E., Dahinden, C., Burger, R., Kupper, R., et al. (1993). Complement fragment C3a stimulates Ca2+ influx in neutrophils via a pertussis-toxin-sensitive G protein. Eur. J. Biochem. 217, 289-294. doi: 10.1111/j.1432-1033.1993.tb18245.x

Ohno, M., Hirata, T., Enomoto, M., Araki, T., Ishimaru, H., and Takahashi, T. A. (2000). A putative chemoattractant receptor, C5L2, is expressed in granulocyte and immature dendritic cells, but not in mature dendritic cells. Mol. Immunol. 37, 407-412. doi: 10.1016/S0161-5890(00)00067-5

Okinaga, S., Slattery, D., Humbles, A., Zsengeller, Z., Morteau, O., Kinrade, M. B., et al. (2003). C5L2, a nonsignaling C5A binding protein. Biochemistry 42, 9406-9415. doi: 10.1021/bi034489v

Olazabal, I. M., Caron, E., May, R. C., Schilling, K., Knecht, D. A., and Machesky, L. M. (2002). Rho-kinase and myosin-II control phagocytic cup formation during CR, but not FcgammaR, phagocytosis. Curr. Biol. 12, 1413-1418. doi: 10.1016/S0960-9822(02)01069-2

Ottonello, L., Corcione, A., Tortolina, G., Airoldi, I., Albesiano, E., Favre, A., et al. (1999). rC5a directs the in vitro migration of human memory and naive tonsillar B lymphocytes: implications for B cell trafficking in secondary lymphoid tissues. J. Immunol. 162, 6510-6517.

Palazzo, A. F., Cook, T. A., Alberts, A. S., and Gundersen, G. G. (2001). mDia mediates Rho-regulated formation and orientation of stable microtubules. Nat. Cell Biol. 3, 723-729. doi: 10.1038/35087035

Palmer, L. J., Damgaard, C., Holmstrup, P., and Nielsen, C. H. (2016). Influence of complement on neutrophil extracellular trap release induced by bacteria. $J$. Periodontal. Res. 51, 70-76. doi: 10.1111/jre.12284

Paral, D., Sohns, B., Crass, T., Grove, M., Köhl, J., Klos, A., et al. (1998). Genomic organization of the human C3a receptor. Eur. J. Immunol. 28, 2417-2423.

Pascual, M., Danielsson, C., Steiger, G., and Schifferli, J. A. (1994). Proteolytic cleavage of CR1 on human erythrocytes in vivo: evidence for enhanced cleavage in AIDS. Eur. J. Immunol. 24, 702-708. doi: 10.1002/eji.1830 240332

Patel, P. C., and Harrison, R. E. (2008). Membrane ruffles capture C3biopsonized particles in activated macrophages. Mol. Biol. Cell 19, 4628-4639. doi: 10.1091/mbc.e08-02-0223

Phillipson, M., Heit, B., Colarusso, P., Liu, L., Ballantyne, C. M., and Kubes, P. (2006). Intraluminal crawling of neutrophils to emigration sites: a molecularly distinct process from adhesion in the recruitment cascade. J. Exp. Med. 203, 2569-2575. doi: 10.1084/jem.20060925

Prado-Alvarez, M., Rotllant, J., Gestal, C., Novoa, B., and Figueras, A. (2009). Characterization of a C3 and a factor B-like in the carpet-shell clam, Ruditapes decussatus. Fish Shellfish Immunol. 26, 305-315. doi: 10.1016/j.fsi.2008.11.015

Prince, J. E., Brayton, C. F., Fossett, M. C., Durand, J. A., Kaplan, S. L., Smith, C. W., et al. (2001). The differential roles of LFA-1 and Mac-1 in host defense against systemic infection with Streptococcus pneumoniae. J. Immunol. 166, 7362-7369. doi: 10.4049/jimmunol.166.12.7362

Proebstl, D., Voisin, M. B., Woodfin, A., Whiteford, J., D’Acquisto, F., Jones, G. E., et al. (2012). Pericytes support neutrophil subendothelial cell crawling and breaching of venular walls in vivo. J. Exp. Med. 209, 1219-1234. doi: 10.1084/jem.20111622

Qiao, Q., Teng, X., Wang, N., Lu, R., Guo, L., Zhang, X., et al. (2018). A novel CRIg-targeted complement inhibitor protects cells from complement damage. FASEB J. 28, 4986-99. doi: 10.1096/fj.14-258046

Raffetseder, U., Röper, D., Mery, L., Gietz, C., Klos, A., Grötzinger, J., et al. (1996). Site-directed mutagenesis of conserved charged residues in the helical region of the human C5a receptor. Arg2O6 determines high-affinity binding sites of C5a receptor. Eur. J. Biochem. 235, 82-90. doi: 10.1111/j.1432-1033.1996. 00082.x

Ratajczak, J., Reca, R., Kucia, M., Majka, M., Allendorf, D. J., Baran, J. T., et al. (2004). Mobilization studies in mice deficient in either C3 or C3a receptor (C3aR) reveal a novel role for complement in retention of hematopoietic stem/progenitor cells in bone marrow. Blood 103, 2071-2078. doi: 10.1182/blood-2003-06-2099

Reca, R., Mastellos, D., Majka, M., Marquez, L., Ratajczak, J., Franchini, S., et al. (2003). Functional receptor for C3a anaphylatoxin is expressed by normal hematopoietic stem/progenitor cells, and $\mathrm{C} 3 \mathrm{a}$ enhances their homing-related responses to SDF-1. Blood 101, 3784-3793. doi: 10.1182/blood-2002-10-3233

Reid, K. B., Bentley, D. R., Campbell, R. D., Chung, L. P., Sim, R. B., Kristensen, T., et al. (1986). Complement system proteins which interact with C3b or C4b A superfamily of structurally related proteins. Immunol. Today 7, 230-234. doi: 10.1016/0167-5699(86)90110-6 
Reinhardt, P. H., Elliott, J. F., and Kubes, P. (1997). Neutrophils can adhere via alpha4beta1-integrin under flow conditions. Blood 89, 3837-3846. doi: 10.1182/blood.V89.10.3837

Reynes, M., Aubert, J. P., Cohen, J. H., Audouin, J., Tricottet, V., Diebold, J., et al. (1985). Human follicular dendritic cells express CR1, CR2, and CR3 complement receptor antigens. J. Immunol. 135, 2687-2694.

Ricklin, D., Hajishengallis, G., Yang, K., and Lambris, J. D. (2010). Complement: a key system for immune surveillance and homeostasis. Nat. Immunol. 11, 785-797. doi: 10.1038/ni.1923

Ricklin, D., Mastellos, D. C., and Lambris, J. D. (2019). Therapeutic targeting of the complement system. Nat. Rev. Drug Discov. doi: 10.1038/s41573-019-0055-y

Rødgaard, A., Christensen, L. D., Thomsen, B. S., Wiik, A., and Bendixen, G. (1991). Complement receptor type 1 (CR1, CD35) expression on peripheral T lymphocytes: both CD4- and CD8-positive cells express CR1. Complement Inflamm. 8, 303-309. doi: 10.1159/000463200

Rosetti, F., and Mayadas, T. N. (2016). The many faces of Mac-1 in autoimmune disease. Immunol Rev 269, 175-193. doi: 10.1111/imr.12373

Ross, G. D., Cain, J. A., Myones, B. L., Newman, S. L., and Lachmann, P. J. (1987). Specificity of membrane complement receptor type three (CR3) for beta-glucans. Complement 4, 61-74. doi: 10.1159/000463010

Ross, G. D., Reed, W., Dalzell, J. G., Becker, S. E., and Hogg, N. (1992). Macrophage cytoskeleton association with CR3 and CR4 regulates receptor mobility and phagocytosis of iC3b-opsonized erythrocytes. J. Leukoc. Biol. 51, 109-117. doi: 10.1002/jlb.51.2.109

Ross, G. D., and Vetvicka, V. (1993). CR3 (CD11b, CD18): a phagocyte and NK cell membrane receptor with multiple ligand specificities and functions. Clin. Exp. Immunol. 92, 181-184. doi: 10.1111/j.1365-2249.1993.tb03377.x

Ross, G. D., Yount, W. J., Walport, M. J., Winfield, J. B., Parker, C. J., Fuller, C. R., et al. (1985). Disease-associated loss of erythrocyte complement receptors (CR1, C3b receptors) in patients with systemic lupus erythematosus and other diseases involving autoantibodies and/or complement activation. J. Immunol. 135, 2005-2014.

Rotty, J. D., Brighton, H. E., Craig, S. L., Asokan, S. B., Cheng, N., Ting, J. P., et al. (2017). Arp $2 / 3$ complex is required for macrophage integrin functions but Is dispensable for FcR phagocytosis and in vivo motility. Dev. Cell 42, 498-513.e6. doi: 10.1016/j.devcel.2017.08.003

Sacks, T., Moldow, C. F., Craddock, P. R., Bowers, T. K., and Jacob, H. S. (1978). Oxygen radicals mediate endothelial cell damage by complement-stimulated granulocytes. An in vitro model of immune vascular damage. J. Clin. Invest. 61, 1161-1167. doi: 10.1172/JCI109031

Sadik, C. D., Miyabe, Y., Sezin, T., and Luster, A. D. (2018). The critical role of C5a as an initiator of neutrophil-mediated autoimmune inflammation of the joint and skin. Semin Immunol. 37, 21-29. doi: 10.1016/j.smim.2018.03.002

Sampson, L. L., Heuser, J., and Brown, E. J. (1991). Cytokine regulation of complement receptor-mediated ingestion by mouse peritoneal macrophages. M-CSF and IL-4 activate phagocytosis by a common mechanism requiring autostimulation by IFN-beta. J. Immunol. 146, 1005-1013.

Sanchez-Madrid, F., Nagy, J. A., Robbins, E., Simon, P., and Springer, T. A. (1983). A human leukocyte differentiation antigen family with distinct alpha-subunits and a common beta-subunit: the lymphocyte function-associated antigen (LFA1), the C3bi complement receptor (OKM1/Mac-1), and the p150,95 molecule. J. Exp. Med. 158, 1785-1803. doi: 10.1084/jem.158.6.1785

Sándor, N., Lukácsi, S., Ungai-Salánki, R., Orgován, N., Szabó B., Horváth, R., et al. (2016). CD11c/CD18 dominates adhesion of human monocytes, macrophages and dendritic cells over CD11b/CD18. PLoS ONE 11:e0163120. doi: 10.1371/journal.pone.0163120

Schenkel, A. R., Mamdouh, Z., and Muller, W. A. (2004). Locomotion of monocytes on endothelium is a critical step during extravasation. Nat. Immunol. 5, 393-400. doi: 10.1038/ni1051

Scribner, D. J., and Fahrney, D. (1976). Neutrophil receptors for IgG and complement: their roles in the attachment and ingestion phases of phagocytosis. J. Immunol. 116, 892-897.

Sekiguchi, R., and Nonaka, M. (2015). Evolution of the complement system in protostomes revealed by de novo transcriptome analysis of six species of Arthropoda. Dev. Comp. Immunol. 50, 58-67. doi: 10.1016/j.dci.2014.12.008

Sengeløv, H., Kjeldsen, L., Kroeze, W., Berger, M., and Borregaard, N. (1994). Secretory vesicles are the intracellular reservoir of complement receptor 1 in human neutrophils. J. Immunol. 153, 804-810.
Shaw, S. K., Ma, S., Kim, M. B., Rao, R. M., Hartman, C. U., Froio, R. M., et al. (2004). Coordinated redistribution of leukocyte LFA-1 and endothelial cell ICAM-1 accompany neutrophil transmigration. J. Exp. Med. 200, 1571-1580. doi: 10.1084/jem.20040965

Shi, Y., Yao, W., Sun, L., Li, G., Liu, H., Ding, P., et al. (2019). The new complement inhibitor CRIg/FH ameliorates lupus nephritis in lupus-prone MRL/lpr mice. BMC Nephrol. 20:424. doi: 10.1186/s12882-019-1599-0

Shin, H. S., Smith, M. R., and Wood, W. B. (1969). Heat labile opsonins to pneumococcus. II. Involvement of C3 and C5. J. Exp. Med. 130, 1229-1241. doi: 10.1084/jem.130.6.1229

Shin, H. S., Snyderman, R., Friedman, E., Mellors, A., and Mayer, M. M. (1968). Chemotactic and anaphylatoxic fragment cleaved from the fifth component of guinea pig complement. Science 162, 361-363. doi: $10.1126 /$ science.162.3851.361

Siciliano, S. J., Rollins, T. E., DeMartino, J., Konteatis, Z., Malkowitz, L., Van Riper, G., et al. (1994). Two-site binding of C5a by its receptor: an alternative binding paradigm for G protein-coupled receptors. Proc. Natl. Acad. Sci. U.S.A. 91, 1214-1218. doi: 10.1073/pnas.91.4.1214

Siegel, I., Liu, T. L., and Gleicher, N. (1981). The red-cell immune system. Lancet 2, 556-559. doi: 10.1016/S0140-6736(81)90941-7

Soruri, A., Kim, S., Kiafard, Z., and Zwirner, J. (2003). Characterization of C5aR expression on murine myeloid and lymphoid cells by the use of a novel monoclonal antibody. Immunol. Lett. 88, 47-52. doi: 10.1016/S0165-2478(03)00052-X

Sozzani, S., Sallusto, F., Luini, W., Zhou, D., Piemonti, L., Allavena, P., et al. (1995). Migration of dendritic cells in response to formyl peptides, C5a, and a distinct set of chemokines. J. Immunol. 155, 3292-3295.

Springer, T., Galfré G., Secher, D. S., and Milstein, C. (1979). Mac-1: a macrophage differentiation antigen identified by monoclonal antibody. Eur. J. Immunol. 9, 301-306. doi: 10.1002/eji.1830090410

Stadtmann, A., Germena, G., Block, H., Boras, M., Rossaint, J., Sundd, P., et al. (2013). The PSGL-1-L-selectin signaling complex regulates neutrophil adhesion under flow. J. Exp. Med. 210, 2171-2180. doi: 10.1084/jem.20130664

Staunton, D. E., Dustin, M. L., Erickson, H. P., and Springer, T. A. (1990). The arrangement of the immunoglobulin-like domains of ICAM1 and the binding sites for LFA-1 and rhinovirus. Cell 61, 243-254. doi: 10.1016/0092-8674(90)90805-O

Stepensky, P. Y., Wolach, B., Gavrieli, R., Rousso, S., Ben Ami, T., Goldman, V., et al. (2015). Leukocyte adhesion deficiency type III: clinical features and treatment with stem cell transplantation. J. Pediatr. Hematol. Oncol. 37, 264-268. doi: 10.1097/MPH.0000000000000228

Strey, C. W., Markiewski, M., Mastellos, D., Tudoran, R., Spruce, L. A., Greenbaum, L. E., et al. (2003). The proinflammatory mediators C3a and C5a are essential for liver regeneration. J. Exp. Med. 198, 913-923. doi: $10.1084 /$ jem. 20030374

Sturla, L., Puglielli, L., Tonetti, M., Berninsone, P., Hirschberg, C. B., De Flora, A., et al. (2001). Impairment of the Golgi GDP-L-fucose transport and unresponsiveness to fucose replacement therapy in LAD II patients. Pediatr. Res. 49, 537-542. doi: 10.1203/00006450-200104000-00016

Sumagin, R., Prizant, H., Lomakina, E., Waugh, R. E., and Sarelius, I. H. (2010). LFA-1 and Mac-1 define characteristically different intralumenal crawling and emigration patterns for monocytes and neutrophils in situ. J. Immunol. 185, 7057-7066. doi: 10.4049/jimmunol.1001638

Sun, J., Ember, J. A., Chao, T. H., Fukuoka, Y., Ye, R. D., and Hugli, T. E. (1999). Identification of ligand effector binding sites in transmembrane regions of the human G protein-coupled C3a receptor. Protein Sci. 8, 2304-2311. doi: $10.1110 /$ ps.8.11.2304

Szakonyi, G., Guthridge, J. M., Li, D., Young, K., Holers, V. M., and Chen, X. S. (2001). Structure of complement receptor 2 in complex with its C3d ligand. Science 292, 1725-1728. doi: 10.1126/science. 1 059118

Taborda, C. P., and Casadevall, A. (2002). CR3 (CD11b/CD18) and CR4 (CD11c/CD18) are involved in complement-independent antibodymediated phagocytosis of Cryptococcus neoformans. Immunity 16, 791-802. doi: 10.1016/S1074-7613(02)00328-X

Takagi, J., Petre, B. M., Walz, T., and Springer, T. A. (2002). Global conformational rearrangements in integrin extracellular domains in outside-in and inside-out signaling. Cell 110, 599-511. doi: 10.1016/S0092-8674(02)00935-2 
Takahashi, K., Kozono, Y., Waldschmidt, T. J., Berthiaume, D., Quigg, R. J., Baron, A., et al. (1997). Mouse complement receptors type 1 (CR1;CD35) and type 2 (CR2;CD21): expression on normal B cell subpopulations and decreased levels during the development of autoimmunity in MRL/lpr mice. J. Immunol. 159, 1557-1569.

Takizawa, F., Tsuji, S., and Nagasawa, S. (1996). Enhancement of macrophage phagocytosis upon iC3b deposition on apoptotic cells. FEBS Lett. 397, 269-272. doi: 10.1016/S0014-5793(96)01197-0

Tanner, J., Weis, J., Fearon, D., Whang, Y., and Kieff, E. (1987). EpsteinBarr virus gp350/220 binding to the B lymphocyte C3d receptor mediates adsorption, capping, and endocytosis. Cell 50, 203-213. doi: 10.1016/0092-8674(87)90216-9

Thorgersen, E. B., Barratt-Due, A., Haugaa, H., Harboe, M., Pischke, S. E., Nilsson, P. H., et al. (2019). The role of complement in liver injury, regeneration, and transplantation. Hepatology 70, 725-736. doi: 10.1002/hep.30508

Torres-Gomez, A., Cabanas, C., and Lafuente, E. M. (2020a). Phagocytic integrins: activation and signaling. Front. Immunol. 11:738. doi: $10.3389 /$ fimmu. 2020.00738

Torres-Gomez, A., Sanchez-Trincado, J. L., Toribio, V., Torres-Ruiz, R., Rodriguez-Perales, S., Yanez-Mo, M., et al. (2020b). RIAM-VASP module relays integrin complement receptors in outside-in signaling driving particle engulfment. Cells 9:1166. doi: 10.3390/cells9051166

Trouw, L. A., Pickering, M. C., and Blom, A. M. (2017). The complement system as a potential therapeutic target in rheumatic disease. Nat. Rev. Rheumatol. 13, 538-547. doi: 10.1038/nrrheum.2017.125

Tuckwell, D., Calderwood, D. A., Green, L. J., and Humphries, M. J. (1995). Integrin alpha $2 \mathrm{I}$-domain is a binding site for collagens. J. Cell Sci. 108 (Pt 4), 1629-1637.

Van der Vieren, M., Le Trong, H., Wood, C. L., Moore, P. F., St John, T., Staunton, D. E., et al. (1995). A novel leukointegrin, alpha d beta 2, binds preferentially to ICAM-3. Immunity 3, 683-690. doi: 10.1016/1074-7613(95) 90058-6

Vennegoor, C. J., van de Wiel-van Kemenade, E., Huijbens, R. J., Sanchez-Madrid, F., Melief, C. J., and Figdor, C. G. (1992). Role of LFA-1 and VLA-4 in the adhesion of cloned normal and LFA-1 (CD11/CD18)-deficient T cells to cultured endothelial cells. Indication for a new adhesion pathway. J. Immunol. 148, 1093-1101.

Vogt, L., Schmitz, N., Kurrer, M. O., Bauer, M., Hinton, H. I., Behnke, S., et al. (2006). VSIG4, a B7 family-related protein, is a negative regulator of $\mathrm{T}$ cell activation. J. Clin. Invest. 116, 2817-2826. doi: 10.1172/JCI25673

Voisin, M. B., Woodfin, A., and Nourshargh, S. (2009). Monocytes and neutrophils exhibit both distinct and common mechanisms in penetrating the vascular basement membrane in vivo. Arterioscler. Thromb. Vasc. Biol. 29, 1193-1199. doi: 10.1161/ATVBAHA.109.187450

von Zabern, I., Hinsch, B., Przyklenk, H., Schmidt, G., and Vogt, W. (1980). Comparison of Naja n. naja and Naja h. haje cobra-venom factors: correlation between binding affinity for the fifth component of complement and mediation of its cleavage. Immunobiology 157, 499-514. doi: 10.1016/S0171-2985(80)80018-0

Vorup-Jensen, T., and Jensen, R. K. (2018). Structural Immunology of Complement Receptors 3 and 4. Front. Immunol. 9:2716. doi: $10.3389 /$ fimmu.2018.02716

Wang, H., Ricklin, D., and Lambris, J. D. (2017). Complement-activation fragment $\mathrm{C} 4 \mathrm{a}$ mediates effector functions by binding as untethered agonist to proteaseactivated receptors 1 and 4. Proc. Natl. Acad. Sci. U.S.A. 114, 10948-10953. doi: 10.1073/pnas.1707364114

Wang, S., Voisin, M. B., Larbi, K. Y., Dangerfield, J., Scheiermann, C., Tran, M., et al. (2006). Venular basement membranes contain specific matrix protein low expression regions that act as exit points for emigrating neutrophils. J. Exp. Med. 203, 1519-1532. doi: 10.1084/jem.2 0051210

Werfel, T., Kirchhoff, K., Wittmann, M., Begemann, G., Kapp, A., Heidenreich, F., et al. (2000). Activated human T lymphocytes express a functional C3a receptor. J. Immunol. 165, 6599-6605. doi: 10.4049/jimmunol.165.11.6599

Wiesmann, C., Katschke, K. J., Yin, J., Helmy, K. Y., Steffek, M., Fairbrother, W. J., et al. (2006). Structure of C3b in complex with CRIg gives insights into regulation of complement activation. Nature 444, 217-220. doi: $10.1038 /$ nature 05263
Wilken, H. C., Götze, O., Werfel, T., and Zwirner, J. (1999). C3a(desArg) does not bind to and signal through the human C3a receptor. Immunol. Lett. 67, 141-145. doi: 10.1016/S0165-2478(99)00002-4

Wilson, J. G., Ratnoff, W. D., Schur, P. H., and Fearon, D. T. (1986). Decreased expression of the $\mathrm{C} 3 \mathrm{~b} / \mathrm{C} 4 \mathrm{~b}$ receptor (CR1) and the C3d receptor (CR2) on B lymphocytes and of CR1 on neutrophils of patients with systemic lupus erythematosus. Arthritis Rheum. 29, 739-747. doi: 10.1002/art.1780290606

Woodfin, A., Voisin, M. B., Imhof, B. A., Dejana, E., Engelhardt, B., and Nourshargh, S. (2009). Endothelial cell activation leads to neutrophil transmigration as supported by the sequential roles of ICAM-2, JAM-A, and PECAM-1. Blood 113, 6246-6257. doi: 10.1182/blood-2008-11-188375

Wu, F., Zou, Q., Ding, X., Shi, D., Zhu, X., Hu, W., et al. (2016). Complement component C3a plays a critical role in endothelial activation and leukocyte recruitment into the brain. J. Neuroinflamm. 13:23. doi: 10.1186/s12974-016-0485-y

Wu, H., Boackle, S. A., Hanvivadhanakul, P., Ulgiati, D., Grossman, J. M., Lee, Y., et al. (2007). Association of a common complement receptor 2 haplotype with increased risk of systemic lupus erythematosus. Proc. Natl. Acad. Sci. U.S.A. 104, 3961-3966. doi: 10.1073/pnas.0609101104

Wu, M. C., Brennan, F. H., Lynch, J. P., Mantovani, S., Phipps, S., Wetsel, R. A., et al. (2013). The receptor for complement component C3a mediates protection from intestinal ischemia-reperfusion injuries by inhibiting neutrophil mobilization. Proc. Natl. Acad. Sci. U.S.A. 110, 9439-9444. doi: 10.1073/pnas. 1218815110

Wu, X., Jiang, N., Deppong, C., Singh, J., Dolecki, G., Mao, D., et al. (2002). A role for the $\mathrm{Cr} 2$ gene in modifying autoantibody production in systemic lupus erythematosus. J. Immunol. 169, 1587-1592. doi: 10.4049/jimmunol.169.3.1587

Xiao, T., Takagi, J., Coller, B. S., Wang, J. H., and Springer, T. A. (2004). Structural basis for allostery in integrins and binding to fibrinogen-mimetic therapeutics. Nature 432, 59-67. doi: 10.1038/nature02976

Xiong, J. P., Stehle, T., Diefenbach, B., Zhang, R., Dunker, R., Scott, D. L., et al. (2001). Crystal structure of the extracellular segment of integrin alpha Vbeta3. Science 294, 339-345. doi: 10.1126/science.1064535

Xiong, J. P., Stehle, T., Zhang, R., Joachimiak, A., Frech, M., Goodman, S. L., et al. (2002). Crystal structure of the extracellular segment of integrin alpha Vbeta3 in complex with an Arg-Gly-Asp ligand. Science 296, 151-155. doi: 10.1126/science. 1069040

Xu, S., Wang, J., Wang, J. H., and Springer, T. A. (2017). Distinct recognition of complement iC3b by integrins alphaXbeta2 and alphaMbeta2. Proc. Natl. Acad. Sci. U.S.A. 114, 3403-3408. doi: 10.1073/pnas.1620881114

Yago, T., Zhang, N., Zhao, L., Abrams, C. S., and McEver, R. P. (2018). Selectins and chemokines use shared and distinct signals to activate $\beta 2$ integrins in neutrophils. Blood Adv. 2, 731-744. doi: 10.1182/bloodadvances.20170 15602

Yakubenko, V. P., Lishko, V. K., Lam, S. C., and Ugarova, T. P. (2002). A molecular basis for integrin alphaMbeta 2 ligand binding promiscuity. J. Biol. Chem. 277, 48635-48642. doi: 10.1074/jbc.M208877200

Yoshida, K., Yukiyama, Y., and Miyamoto, T. (1986). Interaction between immune complexes and C3b receptors on erythrocytes. Clin. Immunol. Immunopathol. 39, 213-221. doi: 10.1016/0090-1229(86)90085-1

Yuan, X., Yang, B. H., Dong, Y., Yamamura, A., and Fu, W. (2017). CRIg, a tissue-resident macrophage specific immune checkpoint molecule, promotes immunological tolerance in NOD mice, via a dual role in effector and regulatory $\mathrm{T}$ cells. Elife 6:e28083. doi: 10.7554/eLife. 29540.028

Zeng, Z., Surewaard, B. G., Wong, C. H., Geoghegan, J. A., Jenne, C. N., and Kubes, P. (2016). CRIg functions as a macrophage pattern recognition receptor to directly bind and capture blood-borne gram-positive bacteria. Cell Host Microbe 20, 99-106. doi: 10.1016/j.chom.2016.06.002

Zhang, C., Wang, C., Li, Y., Miwa, T., Liu, C., Cui, W., et al. (2017). Complement $\mathrm{C} 3 \mathrm{a}$ signaling facilitates skeletal muscle regeneration by regulating monocyte function and trafficking. Nat. Commun. 8:2078. doi: 10.1038/s41467-017-01526-z

Zhang, S., and Cui, P. (2014). Complement system in zebrafish. Dev. Comp. Immunol. 46, 3-10. doi: 10.1016/j.dci.2014.01.010

Zhang, X., Boyar, W., Toth, M. J., Wennogle, L., and Gonnella, N. C. (1997). Structural definition of the C5a C terminus by two-dimensional nuclear magnetic resonance spectroscopy. Proteins 28, 261-267. 
Zipfel, P. F., Wiech, T., Rudnick, R., Afonso, S., Person, F., and Skerka, C. (2019). Complement inhibitors in clinical trials for glomerular diseases. Front. Immunol. 10:2166. doi: 10.3389/fimmu.2019. 02166

Zuiderweg, E. R., Nettesheim, D. G., Mollison, K. W., and Carter, G. W. (1989). Tertiary structure of human complement component C5a in solution from nuclear magnetic resonance data. Biochemistry 28, 172-185. doi: 10.1021/bi00427a025

Zwirner, J., Götze, O., Begemann, G., Kapp, A., Kirchhoff, K., and Werfel, T. (1999). Evaluation of C3a receptor expression on human leucocytes by the use of novel monoclonal antibodies. Immunology 97, 166-172. doi: 10.1046/j.1365-2567.1999.00764.x

Zwirner, J., Werfel, T., Wilken, H. C., Theile, E., and Götze, O. (1998). Anaphylatoxin C3a but not C3a(desArg) is a chemotaxin for the mouse macrophage cell line J774. Eur. J. Immunol. 28, 1570-1577.

Conflict of Interest: The authors declare that the research was conducted in the absence of any commercial or financial relationships that could be construed as a potential conflict of interest.

Copyright (c) 2021 Vandendriessche, Cambier, Proost and Marques. This is an openaccess article distributed under the terms of the Creative Commons Attribution License (CC BY). The use, distribution or reproduction in other forums is permitted, provided the original author(s) and the copyright owner(s) are credited and that the original publication in this journal is cited, in accordance with accepted academic practice. No use, distribution or reproduction is permitted which does not comply with these terms. 